\title{
Variabilidade na produção das oclusivas coronais entre consoantes heterossilábicas por aprendizes campinenses de inglês como L2
}

\author{
Variability in the production of coronal plosives between heterosyllabic \\ consonants by speakers of English as an L2 from the city of Campina Grande
}

Felipe Santos dos Reis*

Rubens Marques de Lucena*

\begin{abstract}
RESUMO: Este trabalho investiga a
ABSTRACT: This work investigates the aquisição de uma estrutura marcada do inglês por parte de aprendizes campinenses de L2, com foco, mais especificamente, na produção de sequências triconsonantais do tipo $\mathrm{Ct} / \mathrm{d}]_{\circ} \mathrm{C}$. Dessa forma, nossa pesquisa sociolinguística busca descrever e explicar a variação na interlíngua de aprendizes campinenses de inglês como L2 no que diz respeito à produção das oclusivas coronais entre consoantes heterossilábicas. Para tanto, 24 informantes foram solicitados(as) a realizar a leitura de uma lista de 43 palavras do inglês contidas em 160 frasesveículo, e metade de tais participantes foram ainda convidados(as) a produzir palavras/fraseados com base em imagens. Lançando mão do tratamento estatístico realizado pelo novo programa de regras variáveis, o Rbrul (JOHNSON, 2015), e da verificação acústica via Praat (BOERSMA; WEENINK, 2013), 1.071 ocorrências do fenômeno foram analisadas. O modelo de acquisition of a marked structure in English by L2 learners from the city of Campina Grande in the state of Paraíba, Brazil, focusing on the production of triconsonantal sequences of the type $\mathrm{Ct} / \mathrm{d}]_{\circ} \mathrm{C}$. More specifically, our sociolinguistic research seeks to describe and explain the variation in the interlanguage of L2 learners of English regarding the production of the coronal plosives between heterosyllabic consonants. For this purpose, 24 informants were asked to read aloud a list of 43 target words embedded in 160 carrier sentences, and half of these participants were also requested to produce words/phrases from images. Therefore, the database consists of 1,071 tokens, which were analyzed using the new variable rule program, Rbrul (JOHNSON, 2015), as well as the speech analysis program Praat (BOERSMA; WEENINK, 2013). The mixed effects model provided by Rbrul selected a
\end{abstract}

\footnotetext{
* Doutor em Linguística pelo Programa de Pós-Graduação em Linguística da Universidade Federal da Paraíba - UFPB (2019).

** Professor Associado da Universidade Federal da Paraíba, onde atua no Departamento de Letras Estrangeiras Modernas (DLEM) e no Programa de Pós-Graduação em Linguística (Proling).
} 
efeitos mistos fornecido pelo Rbrul selecionou uma variável aleatória (informantes) e três variáveis fixas (sonoridades das consoantes anterior e posterior, e proficiência em L2) como sendo estatisticamente significativas para a variação em foco. Partindo da premissa de que as estruturas da língua não são condicionadas apenas por fatores internos ao sistema, nossa discussão recai sobre os fatores internos e externos (efeitos fixos) mais relevantes.

PALAVRAS-CHAVE: Sociolinguística variacionista. Aquisição fonológica. Sequências triconsonantais. Inglês como L2. Interlíngua. random variable (informants) and three fixed variables (sonorities of the preceding and following consonants, and L2 proficiency) as being statistically significant for the application of repairs to the coronal plosives flanked by heterosyllabic consonants. Based on the premise that language structures are not conditioned only by linguistic factors, our discussion focuses on the most relevant internal and external factors (fixed effects).

\section{KEYWORDS:}

Variationist sociolinguistics. Phonological acquisition. Triconsonantal sequences. English as an L2. Interlanguage.

\section{Introdução}

O apagamento das oclusivas coronais do inglês é, sem dúvida, uma das variáveis mais bem descritas na sociolinguística (BAYLEY, 2007). Contudo, esse fenômeno é amplamente investigado no contexto de posição final de palavras, havendo ainda hoje poucos estudos com foco na elisão de [-t,d] em posição medial, sobretudo por parte de falantes de L2. Levando-se em conta tal observação, este trabalho busca investigar o comportamento de aprendizes de inglês naturais do município de Campina Grande, a segunda maior cidade do estado da Paraíba, no que se refere ao processo de aquisição de um padrão variável que ainda apresenta lacunas na literatura. Mais especificamente, focalizaremos a produção de $(-t, d)$ entre duas consoantes heterossilábicas na interlíngua de aprendizes campinenses.

Considerando a complexidade inerente ao processo de Aquisição de Segunda Língua (ASL), a investigação almejada aqui examina o comportamento de aprendizes campinenses de inglês como L2 no processo de aquisição de um padrão variável 
amplamente discutido na literatura fundamentado na noção de unidade mínima ${ }^{1}$ da hierarquia prosódica, tal como preconizada por Bisol (1996) e Selkirk (2003), ou seja, fundamentada a partir da sílaba. Assim, faz-se oportuno ressaltar o status dessa unidade fonológica que constitui o componente fonológico da gramática:

O importante é que, sem dúvida alguma, a sílaba é uma unidade fonológica, ou seja, uma unidade prosódica. E, como todo constituinte, tem um cabeça que, em português, é sempre uma vogal, o elemento de maior sonoridade, e tem seus dominados, as consoantes ou glides que a cercam. A sílaba é, pois, a categoria basilar da hierarquia prosódica e seu domínio é a palavra fonológica, ainda que intermediada pelo pé métrico (BISOL, 1996, p. 245).

A sílaba, portanto, corresponde à menor categoria da hierarquia prosódica. Isso significa que esse constituinte está exaustivamente contido na categoria superior de que faz parte, i.e., do pé métrico, e que não é composto de uma ou mais unidades da categoria imediatamente mais baixa, já que é a mais basilar. Convém ressaltar ainda que nosso interesse por sequências consonantais do tipo $\mathrm{Ct} / \mathrm{d}]_{\sigma} \mathrm{C}$ se deve a algumas diferenças no que concerne à estruturação interna das sílabas no inglês e no português, bem como às estratégias específicas de cada língua para lidar com esse tipo de sequências consonantais.

Entendendo-se regras fonológicas como mapeamentos das relações entre representações em níveis distintos (GOLDSMITH, 1995), temos dois processos que explicam a eliminação e a inserção de sons nas saídas linguísticas de falantes nativos(as) do inglês e do português, respectivamente. No que concerne ao apagamento de /-t,d/ entre duas consoantes heterossilábicas, a regra fonológica amplamente aplicada no inglês como L1 pode ser formalizada como na Figura 1:

\footnotetext{
${ }^{1}$ Como Bisol (1996) esclarece, há teorias que estabelecem a mora como sendo a menor unidade da hierarquia prosódica.
} 
Figura 1 - Regra de elisão de /t,d/ entre duas consoantes no inglês como L1.

$$
\mathrm{C}\left\{\begin{array}{l}
\mathrm{t} / \\
/ \mathrm{d} /
\end{array}\right\} \mathrm{C}(\operatorname{menos} / \mathrm{h} /) \longrightarrow \mathrm{CC}
$$

Fonte: Collins e Mees (1981, p. 180).

É oportuno levar em conta algumas observações no que diz respeito a essa regra. Primeiramente, Collins e Mees (1981) esclarecem que a elisão de /-t,d/ ocorre com menos frequência quando esses segmentos são seguidos por $/ r /$ e, segundo os autores, não é ouvida quando precedem $/ \mathrm{h} /$, de modo que os sintagmas nominais "scratched record" e "a packed house", por exemplo, seriam pronunciados por falantes do Britânico Geral2, respectivamente, como "/'skræft 'rekı:d/" e "/ə 'pækt 'haus/" (p. 180). Segundamente, como é possível perceber com esses exemplos utilizados pelos autores, as sequências consonantais focalizadas na obra em questão ocorrem em fronteira de palavras, de modo que as oclusivas coronais correspondem aos últimos segmentos de codas complexas em posição final de palavras, as quais são seguidas por outras palavras contendo ataques preenchidos por qualquer segmento consonantal, com exceção de /h/. A regra explicitada na Figura 1 é pertinentemente aplicável no contexto da elisão que também ocorre de $(-\mathrm{t}, \mathrm{d})$ quando essas oclusivas coronais se encontram entre duas consoantes heterossilábicas em posição medial de palavras, a exemplo de "postman" /'pəusmən/, "handsome" /'hænsəm/, "sandwich" /'sænwitJ/, "restless" / 'reslis/ e "textbook" /'tcks, bok/.

Já a epêntese vocálica após /t, $\mathrm{d} /$ em posição de coda no Português Brasileiro (doravante, PB), por sua vez, é comumente utilizada como uma estratégia de reparo, devido à presença de uma consoante não licenciada na posição de coda. Dessa forma, pode-se expressar a estratégia de epêntese vocálica após /t,d/ pela seguinte regra:

\footnotetext{
${ }^{2}$ Cruttenden (2014, p. 4, tradução nossa) lança mão do termo "Britânico Geral" (BG) para referir-se ao "[...] sotaque padrão do inglês inglês [i.e., do inglês tal como falado na Inglaterra] conhecido no século passado como Received Pronunciation (RP), mas melhor designado hoje em dia Britânico Geral (BG)."
} 
Figura 2 - Regra de epêntese vocálica após /t,d/ no PB.

$$
\left.\varnothing \longrightarrow\left[\begin{array}{l}
+ \text { silábico } \\
+ \text { alto } \\
- \text { posterior }
\end{array}\right] /\left\{\begin{array}{l}
/ \mathrm{t} / \\
/ \mathrm{d} /
\end{array}\right\}\right]_{\sigma}
$$

Fonte: elaborada pelos autores.

Faz-se necessário esclarecer ainda que as consoantes /t/ e /d/ não são as únicas no PB que favorecem a inserção vocálica quando ocorrem em coda seguida por outra consoante no ataque da sílaba seguinte, como em "ritmo" ['hitımo] , "atmosfera" [atimos'fere], "admiro" [adi'miro] e "advogado" [adivo'gado]. Partindo-se da definição de epêntese enquanto um "acrescentamento de um segmento fonético em posição medial de palavra" (XAVIER; MATEUS, 1990, p. 146 apud MASSINICAGLIARI, 2015, p. 283), podemos observar que há vários tipos de sequências consonantais capazes de provocar a aplicação de uma vogal epentética (que geralmente se manifesta foneticamente como [i], no contexto de sílabas pretônicas e tônicas, ou [I], em sílabas postônicas), devido à presença de uma consoante não aceita na posição de coda - como mencionado, a sílaba do PB permite apenas codas com os traços [-vocálico, +soante] ou [-soante, +contínuo, +coronal], de modo que apenas os arquifonemas /L, R, N, S/ podem preencher tal posição no PB.

Levando-se em conta essas considerações relativas às distintas regras que desmancham contatos marcados entre consonantes no PB e no inglês como L1, conjecturamos que a produção de saídas de inglês como L2 sofrerá influência de alguns fatores, tanto de natureza interna quanto externa. No que se refere às variáveis linguísticas que podem exercer efeito sobre o uso de diferentes variantes na produção de $\mathrm{Ct} / \mathrm{d}]_{\sigma} \mathrm{C}$, tencionamos investigar o papel da sonoridade das consoantes heterossilábicas que flanqueiam (-t,d), como forma de verificar se há uma inter-relação entre a aplicação das estratégias de epêntese vocálica e de elisão e sequências que

\footnotetext{
${ }^{3}$ As transcrições extraídas do corpus têm como base o falar paraibano.
} 
apresentam reversos de sonoridade, ou seja, movimentos de sonoridade na coda e no contato silábico que violam o Princípio de Sequência de Sonoridade (SELKIRK, 1982) e o Princípio do Ciclo de Sonoridade (CLEMENTS, 1990) (doravante PSS e PCS, respectivamente). As variáveis externas, por sua vez, serão controladas a fim de estratificar os(as) informantes nas células sociais, além de identificar aqueles fatores que podem ter uma influência mais forte nas saídas mais próximas e mais distantes daquelas produzidas por falantes de inglês como L1, a exemplo do nível de proficiência, do gênero e da faixa etária, haja vista, partirmos do pressuposto básico de que as estruturas da língua não são condicionadas apenas por fatores internos ao sistema.

Diante do exposto, levando-se em conta a complexidade inerente ao processo de aprendizagem de uma L2 e a escassez de estudos com foco nos dialetos falados na região Nordeste do Brasil, este estudo, sociolinguisticamente orientado, tenciona responder às seguintes perguntas de pesquisa:

a) Quais variantes emergem nas saídas de aprendizes campinenses de inglês como L2 no processo de aquisição de sequências consonantais com $(\mathrm{t}) /(\mathrm{d})$ flanqueados por consoantes heterossilábicas?;

b) Como atua a sonoridade da coda complexa no uso de regras que visam à sua redução?; e

c) Qual o fator externo mais relevante para a aplicação de estratégias de reparo em tal estrutura marcada?

\section{Pressupostos teóricos}

Pulgram (1965) propõe distinguir os termos "encontro" (ou "grupo") e "sequência" no que se refere à designação das possíveis combinações de sons consonantais no interior de palavras. Para o autor, encontros ou grupos consonantais (em inglês, clusters) envolvem a co-ocorrência de consoantes numa mesma sílaba, sendo também conhecidos em português como "encontros consonantais tautossilábicos". Já as sequências consonantais (em inglês, sequences), por sua vez, correspondem ao contato estabelecido entre consoantes posicionadas às margens de 
duas sílabas, i.e., consoante(s) em coda seguida(s) por outra(s) consoante(s) no ataque da sílaba seguinte, contato comumente designado "encontros consonantais heterossilábicos". Assim, os trabalhos que focalizam a co-ocorrência de consoantes no PB geralmente estabelecem a diferença entre esses dois tipos de combinações com base nos modificadores, nomeadamente os classificadores "tautossilábico" e "heterossilábico", ao invés do núcleo, dado que o termo "encontro" é, amiúde, usado invariavelmente antes de ambos os adjetivos.

Csides (2013) defende que as sequências consonantais da língua inglesa encontradas em posição medial de palavras apresentam características menos restritivas que os encontros observados nas margens. De fato, o autor esclarece que as sequências consonantais mediais podem apresentar sonoridade tanto crescente quanto decrescente. Tal liberdade no que concerne à distribuição de consoantes no interior de palavras leva à formação de contatos que ocorrem apenas em posição medial, a exemplo de "medley, motley", athlete, only" (CSIDES, 2013, p. 50).

Outros exemplos de sequências consonantais que ocorrem apenas em posição medial de palavras no inglês são resultantes do processo de composição por justaposição, uma vez que, “[e]m primeiro lugar, virtualmente quaisquer duas palavras podem ser combinadas para formar uma nova palavra com encontro medial" (HAMMOND, 1999, p. 69-70, grifo nosso). As combinações de consoantes [kb] no vocábulo "blackbird" ou [kp] em "checkpoint" ou "pickpocket", por exemplo, não existem em qualquer outra posição de palavras, uma vez que não há vocábulos em inglês que iniciem ou terminem com $[\mathrm{kb}]$ e $[\mathrm{kp}]$. Diferentemente dos exemplos abordados por Csides (2013), as palavras utilizadas por Hammond (1999) para exemplificar sequências consonantais que só ocorrem em posição medial são todas bimorfêmicas. Hammond (1999) ainda chama atenção para sequências consonantais inexistentes em

\footnotetext{
${ }^{4}$ As sequências [dl, tl] são classificadas como "encontros consonantais falsos" por Sheer (2004), Harris (1994), Szigetvári (2007), dentre outros. Tal classificação não será debatida aqui.
} 
posições inicial e final de palavras que são formadas por outro processo morfológico, i.e., sufixação, como a sequência [dh] em palavras como "childhood".

Essa liberdade na combinação de consoantes no contexto de sílabas em contato pode estar associada a “[...] uma das suposições mais básicas dentro da teoria da sílaba: designadamente, a de que as restrições fonotáticas são amplamente baseadas na sílaba" (BLEVINS, 2003, p. 375, tradução nossa). Tal suposição, cuja validade é questionada por Blevins (2003), sugere que as restrições fonotáticas, de modo geral, operam dentro das sílabas, e não entre elas (BERG, 1998). De fato, diversas restrições fonotáticas da língua inglesa são definidas com base nessa unidade fonológica, como, por exemplo, a não aceitação de /h/ ou glides em codas, bem como de /y/ em ataques.

Além de não haver restrições para a combinação de consonantes resultante de composição (HAMMOND, 1999) ou de haver maior liberdade nas restrições relativas ao contato entre consoantes em coda seguidas por outras em ataque (CSIDES, 2013; BERG, 1998), Cruttenden (2014) também ressalta a característica de que as sequências consonantais em posição medial de palavras podem ser mais longas que aquelas encontradas nas posições inicial e final, haja vista compreenderem ambas as margens. De fato, Pierrehumbert (1994, p. 168) fundamenta-se no pressuposto de que "o produto cruzado de codas e ataques é o ponto de partida para qualquer descrição de encontros consonantais mediais ${ }^{5} . "$

De modo geral, os vocábulos que apresentam o tipo específico de sequências consonantais focalizado aqui, com as oclusivas coronais entre duas consoantes heterossilábicas, são bimorfêmicos: uma sílaba contém a coda complexa encerrada por /t/ ou /d/, e a sílaba seguinte pode corresponder a sufixos ("soft+ness", "exact+ly", "invest+ment", "trust+ful", etc.) ou cabeças de substantivos compostos ("text+book", "soft+cover", "hand $\underline{\text { ball", }}$ etc.).

\footnotetext{
${ }^{5}$ Convém observar que, embora a autora opte pelo uso do termo "cluster", o contato de consoantes entre codas e ataques é designado aqui "sequência consonantal”.
} 
Ainda que diversos estudos já tenham sido conduzidos com foco na regra variável de apagamento de [-t,d], o que se pode perceber é que a variável investigada restringe-se a (-t,d) em encontros biconsonantais finais, ou seja, em posição final de palavras, haja vista serem bastante frequentes em inglês, além de sua redução ser amplamente disseminada (ROBERTS, 1994; TEMPLE, 2009). Entretanto, estudos sobre o apagamento das oclusivas coronais em posição medial de palavras não são tão recorrentes, sobretudo entre aprendizes de inglês durante o processo de aquisição da L2.

\section{Metodologia}

A fim de realizar a pesquisa variacionista proposta aqui, dados foram coletados com aprendizes de inglês naturais do município de Campina Grande, a segunda maior cidade do estado da Paraíba. Um total de 24 campinenses $^{6}$ foi convidado a participar do estudo e, mediante aceitação do convite e assinatura do Termo de Consentimento Livre e Esclarecido, solicitamos a esses(as) informantes a leitura de uma lista de 160 palavras em inglês, todas inseridas na seguinte frase-veículo: “The word is...". De modo geral, 43 dessas frases-veículo contêm vocábulos $\operatorname{com}^{7}(-\mathrm{t}, \mathrm{d})$ flanqueados por duas consoantes heterossilábicas. Como forma de evitar a conscientização por parte dos(as) informantes acerca do padrão variável de interesse, as 43 palavras cruciais foram mescladas com 117 palavras distratoras.

Além da leitura controlada, um segundo instrumento de coleta de palavras em língua inglesa foi aplicado a metade da amostra, através da exibição de um conjunto de três imagens por slide, com o objetivo de capturar dados orais advindos de um

\footnotetext{
${ }^{6}$ Os símbolos utilizados na análise com referência ao grupo de participantes incluem: M1-M4 = mulheres de nível de proficiência básico em inglês como L2; M5-M8 = mulheres de nível intermediário; e M9-M12 = mulheres de nível avançado; H1-H4 = homens de nível de proficiência básico em L2; H5-H8 = homens de nível intermediário; e H9-H12 = homens de nível avançado. Todos os 24 sujeitos se autodeclararam cisgênero.

${ }^{7}$ As 43 palavras contendo C podem ser verificadas em Anexo A.
} 
contexto semiespontâneo de fala. Um total de 1.071 ocorrências do fenômeno foi capturado através do software Audacity, v. 2.0.6 (MAZZONI; DANNENBERG, 2011). Posteriormente, os dados registrados foram submetidos à análise acústica via Praat, v. 5.3.56 (BOERSMA; WEENINK, 2013), e, então, codificados a fim de receber tratamento estatístico por meio da plataforma R (R CORE TEAM, 2018), v. Rx64 3.5.2, com auxílio do pacote Rbrul (JOHNSON, 2015).

Além da aplicação de tais instrumentos, os 24 sujeitos campinenses também foram solicitados a preencher um questionário, aplicado nas versões on-line ${ }^{8}$ e impressa em papel, conforme a preferência de cada indivíduo. Vejamos, no Quadro 1, algumas informações coletadas sobre tais aprendizes:

Quadro 1 - Informações sobre a população de informantes.

\begin{tabular}{|c|c|c|c|c|c|}
\hline $\begin{array}{c}\text { Nomes } \\
\text { codificados }\end{array}$ & Idades & Gêneros & $\begin{array}{c}\text { Níveis de } \\
\text { proficiência }\end{array}$ & $\begin{array}{l}\text { Experiência } \\
\text { em países } \\
\text { cuja L1 é o } \\
\text { inglês }\end{array}$ & $\begin{array}{l}\text { Curso de } \\
\text { idiomas }\end{array}$ \\
\hline M1 & 21 & \multirow{12}{*}{ Mulheres cis } & \multirow{4}{*}{ Básico } & & \\
\hline M2 & 31 & & & & $\checkmark$ \\
\hline M3 & 33 & & & & $\checkmark$ \\
\hline M4 & 55 & & & $\checkmark$ & \\
\hline M5 & 24 & & \multirow{4}{*}{$\begin{array}{c}\text { Intermediári } \\
\mathrm{o}\end{array}$} & & $\checkmark$ \\
\hline M6 & 24 & & & $\checkmark$ & $\checkmark$ \\
\hline M7 & 31 & & & & \\
\hline M8 & 34 & & & $\checkmark$ & $\checkmark$ \\
\hline M9 & 18 & & \multirow{4}{*}{ Avançado } & & $\checkmark$ \\
\hline M10 & 31 & & & $\checkmark$ & $\checkmark$ \\
\hline M11 & 32 & & & $\checkmark$ & $\checkmark$ \\
\hline M12 & 35 & & & $\checkmark$ & $\checkmark$ \\
\hline $\mathrm{H} 1$ & 28 & \multirow{4}{*}{ Homens cis } & \multirow{4}{*}{ Básico } & $\checkmark$ & \\
\hline $\mathrm{H} 2$ & 33 & & & & $\checkmark$ \\
\hline H3 & 57 & & & $\checkmark$ & $\checkmark$ \\
\hline $\mathrm{H} 4$ & 60 & & & $\checkmark$ & \\
\hline
\end{tabular}

${ }^{8}$ Disponível on-line, o questionário aplicado em sua versão digital pode ser acessado por meio do site: https://docs.google.com/forms/d/e/1FAIpQLSekqcVAN5hbxOk3ZCv4W2L3awodbQlTPKZIE5XinFhD -vMn6w/viewform. 


\begin{tabular}{|c|c|c|c|c|}
\hline H5 & 25 & \multirow{4}{*}{$\begin{array}{l}\text { Intermediári } \\
\text { o }\end{array}$} & $\checkmark$ & $\checkmark$ \\
\hline $\mathrm{H} 6$ & 32 & & & \\
\hline H7 & 37 & & $\checkmark$ & $\checkmark$ \\
\hline $\mathrm{H} 8$ & 42 & & $\checkmark$ & \\
\hline H9 & 31 & \multirow{4}{*}{ Avançado } & $\checkmark$ & \\
\hline H10 & 32 & & & $\checkmark$ \\
\hline H11 & 36 & & $\checkmark$ & $\checkmark$ \\
\hline $\mathrm{H} 12$ & 39 & & $\checkmark$ & $\checkmark$ \\
\hline
\end{tabular}

Fonte: elaborado pelos autores.

Como se pode observar, 15 informantes tiveram a experiência de visitar países onde o inglês seja falado como L1 e, consequentemente, de interagir com falantes nativos(as) durante períodos que variam de duas semanas a seis meses. Todos os 24 sujeitos informaram ter interesse no inglês por razões que incluem desde as demandas do mercado de trabalho até questões de prazer e de conhecimento. Além disso, todos os indivíduos investigados afirmaram ter estudado a língua inglesa durante os ensinos fundamental e médio na escola, tendo 16 de tais informantes buscado maior aprofundamento em escolas particulares de idiomas.

\subsection{Caracterização da variável dependente}

As palavras que apresentam as sequências consonantais de interesse para o presente estudo são amplamente caracterizadas por serem bimorfêmicas de modo geral, podendo ser formadas por sufixos (-ness, -ly, -ment, -ful, etc.) ou por meio da composição ("text+book", "soft+cover", "hand+ball", etc.). Assim, as oclusivas coronais ocorrem na última posição das codas mediais complexas que compõem a estrutura silábica de radicais (no caso de palavras com sufixos) ou de modificadores (nos substantivos compostos). Os sufixos e cabeças, por sua vez, apresentam o ataque preenchido por uma consoante, resultando em sequências do tipo detalhado na Figura 3: 
Figura 3 - Sequência consonantal em foco.

$$
\begin{gathered}
\mathrm{C}]_{\sigma} \\
{\left[\begin{array}{l}
\text { - soan } \\
- \text { cont } \\
+ \text { cor } \\
+ \text { ant }
\end{array}\right]}
\end{gathered}
$$

Fonte: elaborada pelos autores.

Identificamos no nosso corpus a ocorrência de três variantes nas saídas produzidas por aprendizes campinenses de inglês como L2, quais sejam:

a) sem aplicação de qualquer regra:

$-\mathrm{Ct} / \mathrm{d}]_{\sigma} \mathrm{C}$;

b) com aplicação da regra da L1 de epêntese vocálica:

$\left.-\emptyset \longrightarrow[\mathrm{i}] /\left\{\begin{array}{c}{[\mathrm{t}]} \\ {[\mathrm{d}]}\end{array}\right\}-\right]_{\sigma} ;$

c) com aplicação da regra da L2 de simplificação da sequência consonantal: $-\left\{\begin{array}{c}/ \mathrm{t} / \\ / \mathrm{d} /\end{array}\right\} \longrightarrow \emptyset / \mathrm{C}_{-}-\left\{\begin{array}{c}]_{+} \\ +\end{array}\right\} \mathrm{C}$.

Percebe-se que as variantes podem ser vistas num gradiente que vai desde a inserção de um segmento ausente na entrada, passando pela produção de todos os sons presentes na sequência consonantal da subjacência, até o apagamento de uma consoante na superfície.

\subsection{Variáveis preditoras}

O Quadro 2 sintetiza as nove variáveis preditoras deste estudo acompanhadas de seus respectivos níveis:

Quadro 2 - Variáveis controladas no estudo.

\begin{tabular}{|l|l|l|}
\hline \multicolumn{1}{|c|}{ Variáveis } & \multicolumn{1}{c|}{ Níveis } & \multicolumn{1}{c|}{ Tipo } \\
\hline Informantes & M1-M12, H1-H12 & Aleatória \\
\hline Gêneros & Mulheres cis e homens cis & Categórica \\
\hline Níveis de proficiência em L2 & Básico, intermediário e avançado & Categórica \\
\hline Idades & $\begin{array}{l}\text { Mín. 18; mediana 32; média 34,183; } \\
\text { máx. 60 }\end{array}$ & Contínua \\
\hline
\end{tabular}




\begin{tabular}{|l|l|l|}
\hline Contextos anteriores & $\begin{array}{l}\text { Consoantes coronais, dorsais e } \\
\text { labiais }\end{array}$ & Categórica \\
\hline $\begin{array}{l}\text { Índices de sonoridade da consoante } \\
\text { anterior }\end{array}$ & $11-/ \mathrm{r} /, 7-/ \mathrm{n} /, 3-/ \mathrm{s}, \mathrm{f} / \mathrm{e} \mathrm{1-/ \textrm {k } /}$ & Categórica \\
\hline $\begin{array}{l}\text { Contextos posteriores } \\
\text { Níveis de sonoridade da consoante } \\
\text { seguinte }\end{array}$ & $\begin{array}{l}\text { Sonoridade maior, igual a, ou } \\
\text { menor que a de (t,d) }\end{array}$ & Categórica \\
\hline $\begin{array}{l}\text { Alterações nas produções das dérica } \\
\text { palavras }\end{array}$ & $\begin{array}{l}\text { Sem alteração, redução de outra C } \\
\text { da sequência, acento modificado, C } \\
\text { alterada, V alterada, duas ou mais } \\
\text { alterações }\end{array}$ & Categórica \\
\hline
\end{tabular}

Fonte: elaborado pelos autores.

\section{Resultados}

Levando-se em conta o fato de que todos(as) os(as) informantes produziram 43 palavras cruciais no primeiro instrumento de coleta em inglês e de que metade de tais aprendizes produziu de zero a cinco palavras cruciais no segundo instrumento de coleta, capturamos um total de 1.071 ocorrências do fenômeno, delimitadas dentre as três variantes no Gráfico 1:

Gráfico 1 - Frequência global das três variantes.

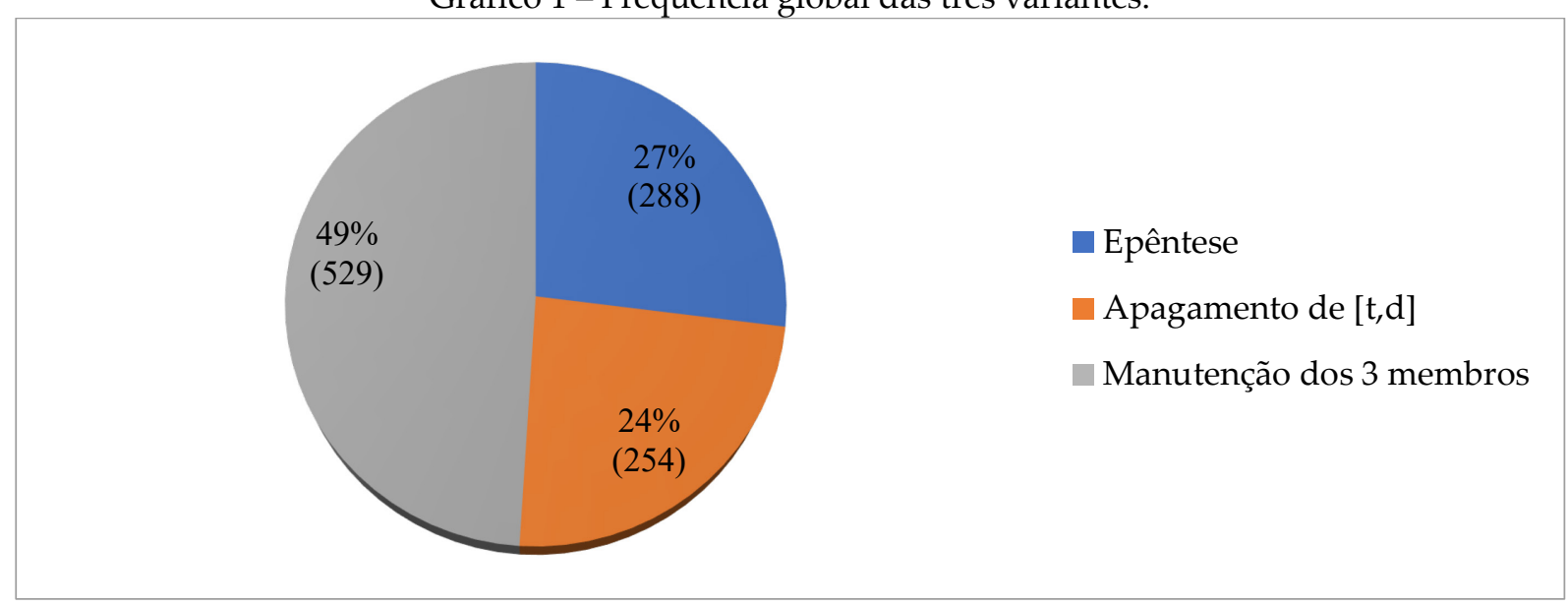

Fonte: elaborado pelos autores.

Como é possível observar, 49\% das 1.071 ocorrências de sequências consonantais com $(t, d)$ entre consoantes heterossilábicas evidenciam a produção de seus três membros, ao passo que 51\% dos dados, por sua vez, apresentam saídas com 
o emprego de estratégias que visam ao reparo dessa estrutura marcada. Mais especificamente, $27 \%$ desse total de dados envolvem a produção de uma vogal epentética após [t] ou [d] - ocasionando, com isso, uma inserção silábica - e 24\%, o apagamento dessas oclusivas. Esses percentuais permitem constatar que há variação na interlíngua de aprendizes campinenses de inglês como L2.

Os resultados iniciais despertam interesse por dois motivos: primeiramente, o emprego de estratégias de reparo para simplificar a estrutura silábica do inglês foi semelhante ao de manutenção de tal estrutura complexa; segundamente, o índice de epêntese foi um pouco mais alto que o de apagamento de $[t, d]$. Antes de nos aprofundarmos nessas questões, vejamos, na Figura 4, o comportamento da variante caracterizada pela retenção dos três membros da sequência consonantal $C t]_{\sigma} C$ na produção de "swiftness":

Figura 4 - Produção da oclusiva coronal [t] na palavra "swiftness" por H12.

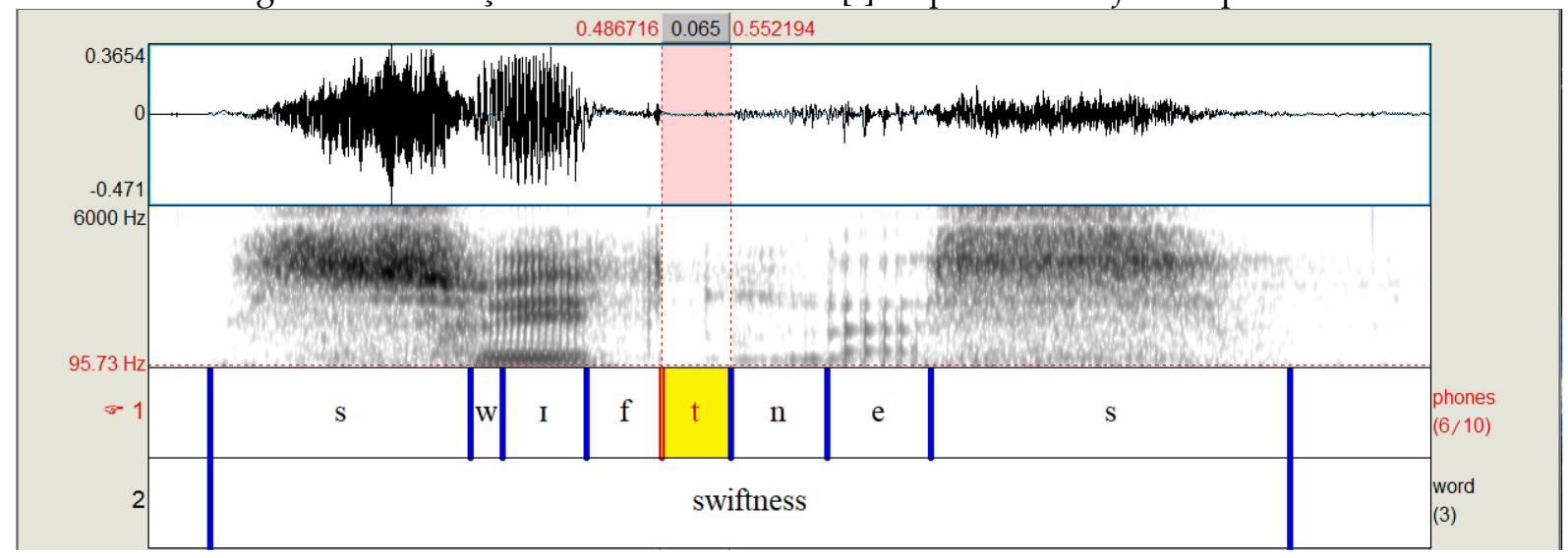

Fonte: extraída de análise no programa Praat.

A Figura 4 mostra o oscilograma e o espectrograma referentes à produção de "swiftness" por H12, durante a aplicação do primeiro instrumento em inglês, com frases-veículo. Para descrevermos os eventos acústicos relativos à produção de $[\mathrm{t}]$ na sequência em questão, convém observarmos três propriedades acústicas das oclusivas, quais sejam, intervalo da oclusiva, transiente e intervalo de africação, destacadas na Figura 5: 
Figura 5 - Forma da onda e do espectrograma de [t] na sequência [ft.n] em "swiftness".

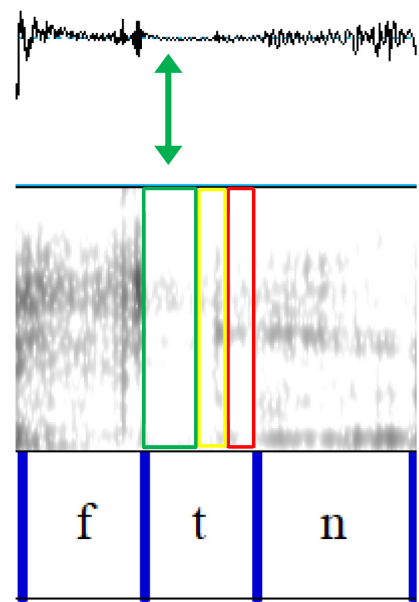

Fonte: extraída de análise no programa Praat.

A seta dupla verde da Figura 5 indica o ponto em que há um mínimo de energia do sinal acústico, que pode ser observado tanto na forma da onda quanto no espectrograma. O retângulo verde compreende esse ponto, designado "intervalo da oclusiva", que é caracterizado por um período de silêncio, quando "[...] pouco ou nenhum som irradia do trato vocal obstruído" (KENT; READ, 2015, p. 234). De modo geral, o intervalo acústico de silêncio, “[...] correspondente à completa obstrução do trato vocal" (KENT; READ, 2015, p. 234), antecede os eventos de ruído demarcados pelos retângulos amarelo e vermelho: inicialmente, temos um transiente, ou seja, uma curta explosão de energia acústica produzida na soltura inicial da pressão do ar após a constrição; e, em seguida, ocorre o chamado "intervalo de africação", que diz respeito a uma fase de energia em que um ruído de turbulência é gerado no lugar da constrição oral. No caso das oclusivas alveolares, a explosão de energia costuma ser de alta frequência (KENT; READ, 2015), como se pode observar mais claramente no retângulo vermelho.

As Figuras 4 e 5 trazem um exemplo de palavra que foi produzida por um aprendiz campinense de nível avançado e que contém as três consoantes na sequência consonantal do tipo $\mathrm{Ct}]_{\sigma} \mathrm{C}$. Em suma, é possível identificar a presença da oclusiva 
coronal através da observação do intervalo da oclusiva e de um breve pulso de energia subsequente, i.e., do transiente. Como visto, esses eventos acústicos correspondem, respectivamente, à obstrução completa do trato vocal - com o toque da ponta da língua na arcada alveolar e sem a energia de vozeamento - e à soltura do ar com a abertura de tal construção. Vejamos outra sequência em que houve a aplicação da estratégia de apagamento de $[\mathrm{t}]$ :

Figura 6 - Forma da onda e do espectrograma da produção de "the word is postpone" por H12.

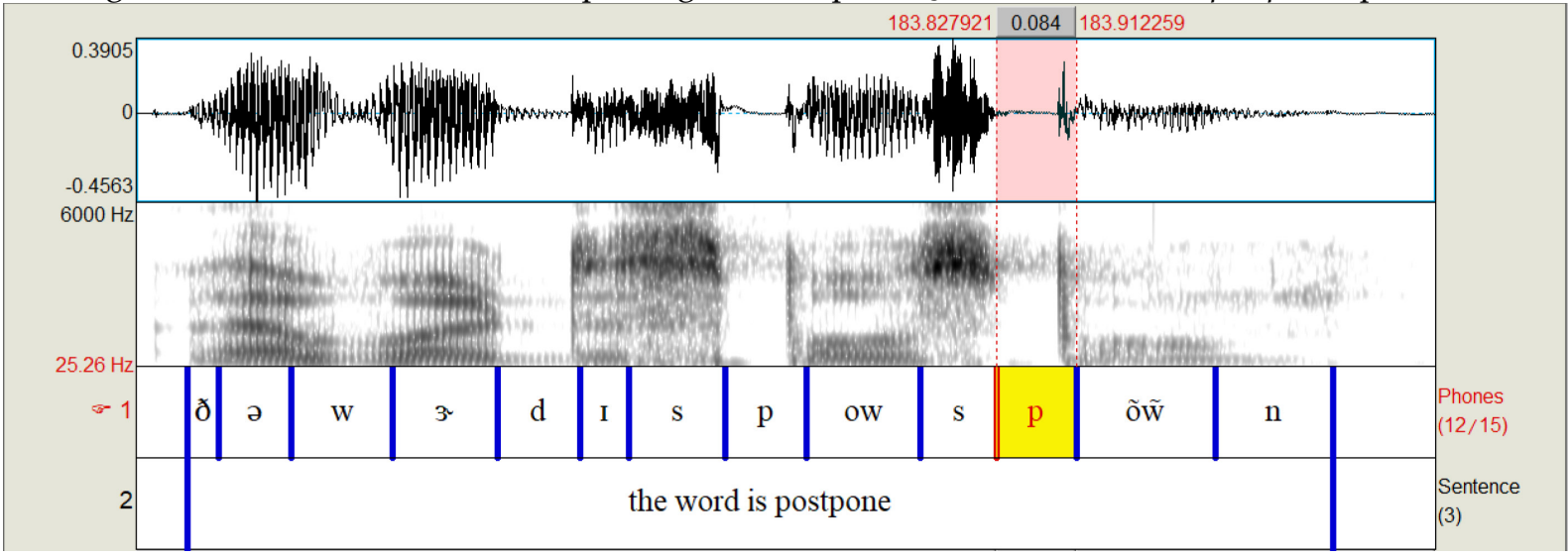

Fonte: extraída de análise no programa Praat.

Considerando as propriedades acústicas detalhadas anteriormente acerca das características espectrais de [t] na palavra "swiftness", percebe-se claramente que não há a presença de dois intervalos da oclusiva, após o ruído de turbulência produzido pela sibilante [s] no vocábulo "postpone". Considerando o fato de que a sequência na palavra em questão envolve o contato entre duas oclusivas heterossilábicas, i.e., /t/ e /p/, a produção desses dois sons na superfície implicaria dois períodos de silêncio e duas breves explosões, como na Figura 7: 
Figura 7 - Eventos acústicos de duas consoantes oclusivas na sequência triconsonantal [ft.k].

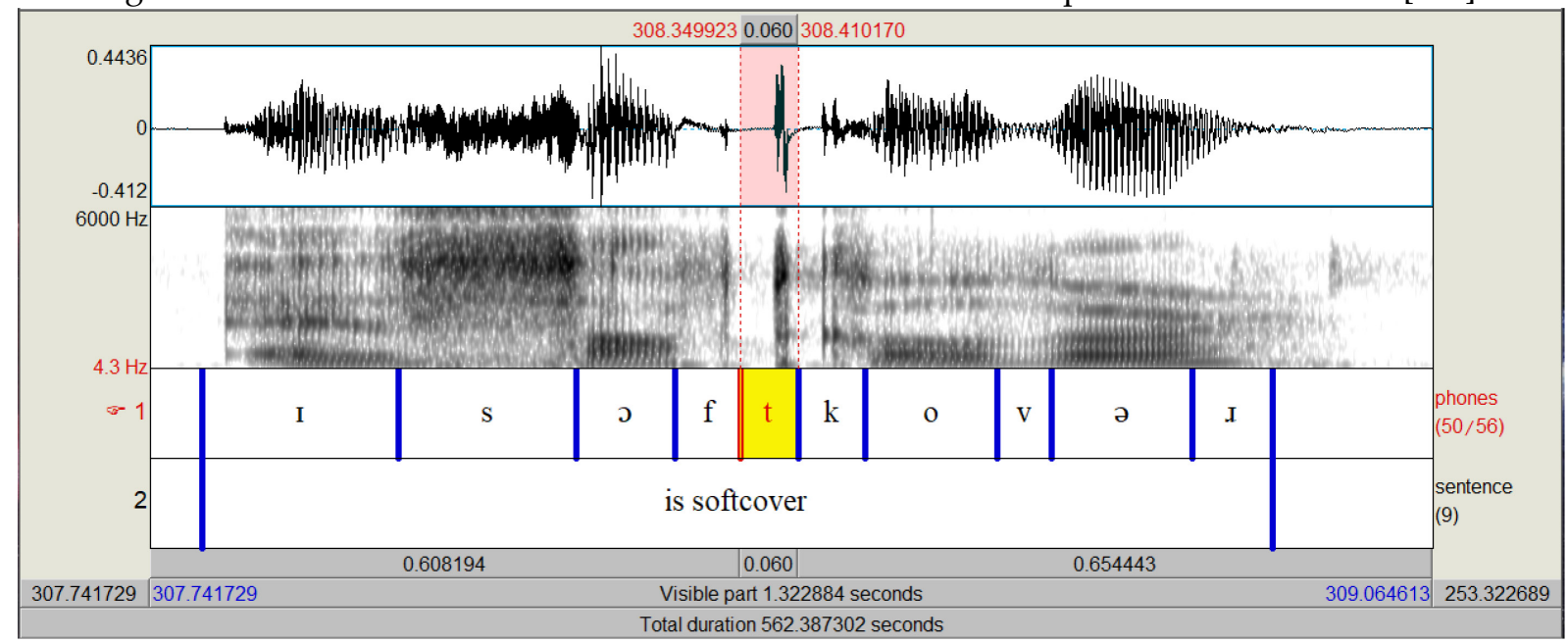

Fonte: extraída de análise no programa Praat.

A Figura 7 exibe dois intervalos da oclusiva, visualmente perceptíveis por meio das faixas mais claras sobre os fones [t] e [k], além de dois transientes após esses períodos de silêncio causados por obstruções do trato vocal. Comparando as sequências /st.p/ e /ft.k/ das Figuras 6 e 7, respectivamente, torna-se mais evidente o uso da estratégia de apagamento da oclusiva coronal por H12 na palavra "postpone", em comparação com o que ocorre no vocábulo "softcover", em que há retenção de todos os fones da sequência triconsonantal.

Por fim, a última variante a ser ilustrada aqui envolve a inserção de vogal epentética entre a oclusiva coronal e a consoante heterossilábica posterior, criando, assim, uma nova sílaba no pós-léxico, como podemos ver na Figura 8, que traz a sequência /st.m/ da palavra "postman" produzida com a aplicação da estratégia de epêntese vocálica por H2 durante a leitura das frases-veículo: 
Figura 8 - Inserção de vogal epentética em "postman" por H1.

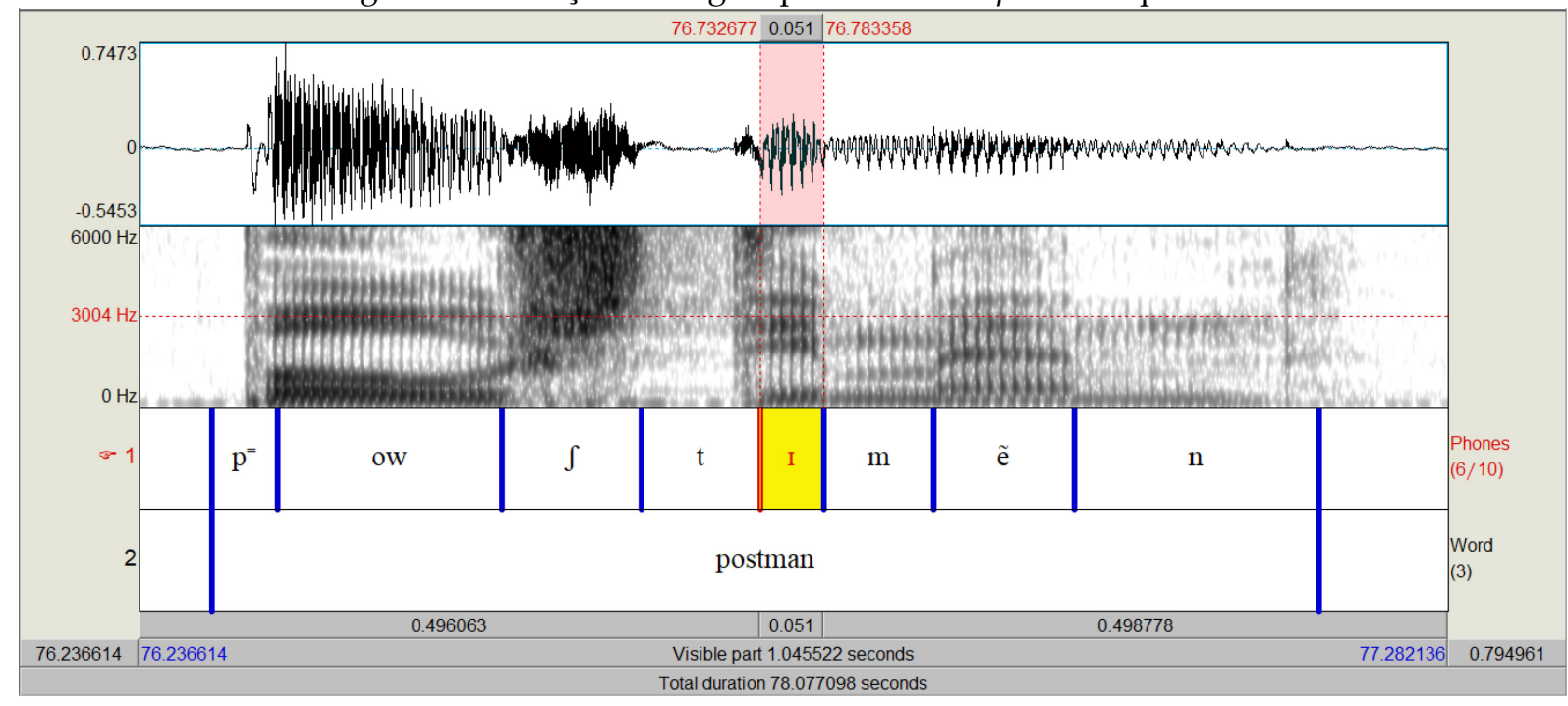

Fonte: extraída de análise no programa Praat.

Observam-se, após a explosão de energia acústica e a fricção da oclusiva [t], os formantes de uma vogal epentética com duração de 51 ms, destacada em amarelo e rosa. Outro segmento relevante para nossa investigação em torno da interlíngua de falantes campinenses de inglês como L2 diz respeito à palatalização de /S/ diante da oclusiva coronal, que não ocorre no inglês com L1, podendo ter se manifestado na interlíngua de $\mathrm{H} 2$ devido não apenas a uma interferência de seu dialeto nativo, mas também do correlato ortográfico $<t>$. Com isso, a superficialização da oclusiva alveolar levou à palatalização da sibilante diante do contexto coronal seguinte, que diz respeito a um processo típico do dialeto paraibano (HORA, 2003). De fato, a frequência da sibilante palatal costuma ser relativamente mais baixa que a da alveolar, ambas visualmente perceptíveis nas partes mais escuras demarcadas no espectrograma da Figura 9: 
Figura 9 - Frequências das fricativas palatal e alveolar na palavra "Christmas", produzida por H1.

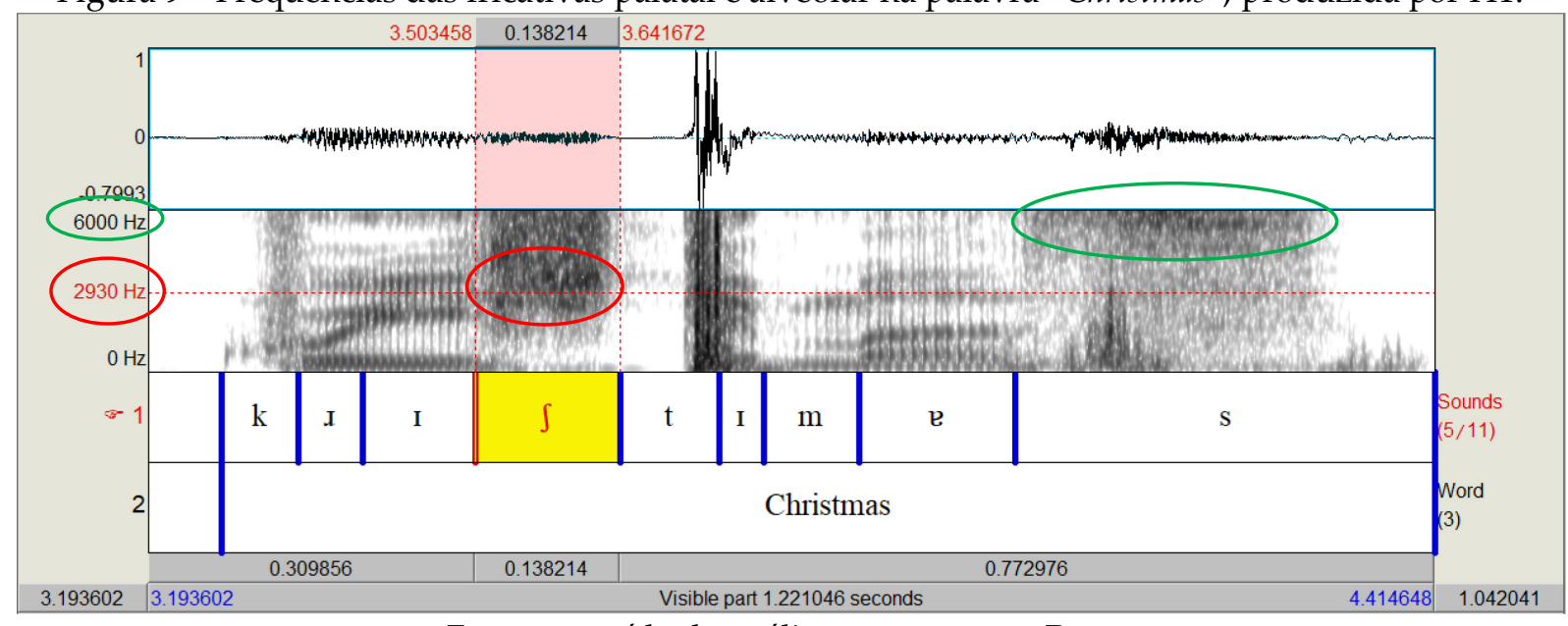

Fonte: extraída de análise no programa Praat.

De fato, a frequência da sibilante palatal costuma ser relativamente mais baixa que a da alveolar, ambas visualmente perceptíveis nas partes mais escuras demarcadas no espectrograma, que correspondem às concentrações de energia na Figura 9. No que concerne aos valores de energia dessas fricativas, Kent e Read (2015, p. 266-267) esclarecem que: “[...] para falantes adultos masculinos, a principal região de energia de ruído para as fricativas alveolares está acima de $4 \mathrm{kHz}$. Em contraste, as fricativas palatais possuem energia de ruído significante se estendendo para cerca de $3 \mathrm{kHz} . "$ Por fim, entendemos que, para o aprendiz, a palavra "Christmas" apresentaria o encontro /st/ não permitido na coda do PB. A epêntese inserida por H1 no vocábulo, portanto, torna o molde silábico mais próximo daquele observado em sua língua nativa, na medida em que a oclusiva coronal é extraviada para o ataque da sílaba gerada pela aplicação dessa estratégia de reparo e que a sílaba passa a ser travada por uma coda simples, preenchida pela sibilante, resultando em ['k.IIf.tI.mes], com todas as sílabas atendendo às restrições fonotáticas do PB, a exemplo de "cristianismo" ([krif.ti.ã'niz.mo]).

Como mencionado anteriormente, após a identificação e a transcrição das variantes produzidas na interlíngua dos 24 sujeitos campinenses com o auxílio do Praat, v. 5.3 .56 (BOERSMA; WEENINK, 2013), os dados foram codificados e 
submetidos ao tratamento estatístico. Diferentemente de programas antecessores, tais como VaRbrul (CEDERGREN; SANKOFF, 1974) e GoldVarb X (SANKOFF; TAGLIAMONTE; SMITH, 2005), o pacote estatístico Rbrul (JOHNSON, 2015) possibilita modelagens de efeitos mistos, na medida em que realiza análises de regressão logística levando em conta não apenas as variáveis de efeitos fixos, mas também as variáveis aninhadas em outras (de efeito aleatório), que o programa permite distinguir numa mesma rodada.

Outra lacuna que o Rbrul preenche envolve a incorporação de outras unidades na apresentação dos resultados: além dos pesos relativos, tipicamente fornecidos nas modelagens de efeitos fixos adotadas pelo VaRbrul e GoldVarb X, o software também fornece valores de log-odds, definido por Johnson (2015) como “[...] a unidade padrão para relatar os resultados de regressões logísticas", para as variáveis fixas (categóricas e contínuas), e intercepts, para variáveis aleatórias. Há ainda valores em termos de proporção (taxa de aplicação das variantes em porcentagem), de desvio padrão (medida que indica o quão ajustado é o modelo aos dados, semelhantemente ao logaritmo de verossimilhança do GoldVarb X) e de média geral de aplicação da variável resposta nos dados do corpus.

As variáveis selecionadas como sendo relevantes para a aplicação de reparos em $\mathrm{Ct} / \mathrm{d}]_{\sigma} \mathrm{C}$ na análise step-up/step-down incluem: informantes (aleatória) e índices de sonoridade da consoante anterior $(p<0,001)$ + níveis de sonoridade da consoante posterior $(p<0,001)+$ níveis de proficiência em L2 $(p<0,001)$.

As variáveis "gêneros", "idades", "contextos anteriores", "contextos posteriores" e "alterações nas produções das palavras" não foram selecionadas na análise de regressão logística realizada pelo software por meio do método denominado "step up", que realiza cálculos progressivos como forma de testar a significância dos fatores e, então, distribuí-los por ordem de seleção. Segundo Hosmer e Lemeshow (2000, p. 1): “[o]s métodos de regressão se tornaram um componente integral de 
qualquer análise de dados relacionada à descrição da relação entre uma variável resposta e uma ou mais variáveis explicativas." Com relação aos métodos step-up e step-down, conhecidos em estatística como métodos stepwise, os autores ainda explicam:

Qualquer procedimento stepwise para a seleção ou exclusão de variáveis de um modelo baseia-se em um algoritmo estatístico que verifica a "importância" de variáveis e que as inclui ou exclui com base em uma regra de decisão fixa. A "importância" de uma variável é definida em termos de uma medida da significância estatística do coeficiente para a variável (HOSMER; LEMESHOW, 2000, p. 116).

A seleção fornecida pelo procedimento step-up foi confirmada pelo step-down (com cálculos regressivos), tendo as cinco mencionadas variáveis também sido eliminadas nessa etapa subsequente da análise binomial, o que significa que os níveis desses preditores não são relevantes para o condicionamento da variação, ou seja, para a aplicação de estratégias de reparo em (t) ou (d) entre consoantes heterossilábicas. Como explicam Lima e Lucena (2008), “[o] ideal é que a seleção feita pelo step-up e a eliminação, pelo step-down, apresentem distribuição complementar: os grupos de fatores não selecionados são também eliminados", tendo ocorrido precisamente isso com nossos dados, tendo tal correspondência sido explicitada no Rbrul pela expressão "Step-up and step-down match!" ao final dos resultados.

A fim de atingir os objetivos formulados, nossa discussão focalizará as variáveis interna e externa estatisticamente significativas.

\subsection{Sonoridade da consoante anterior a $(t, d)$}

A regra variável considerada na rodada binária envolve a aplicação de estratégias de reparos nas oclusivas coronais $(\mathrm{t}, \mathrm{d})$ quando flanqueadas por duas consoantes heterossilábicas. Sabemos que as oclusivas podem ocupar a posição de coda (simples ou complexa) no inglês, como nas palavras como "cat", "cap", "ad" e "fact", por exemplo, não sendo necessários quaisquer tipos de reparo. Em português, 
no entanto, as oclusivas não são licenciadas em posição pós-vocálica, pois violam as condições de boa formação da coda silábica. Assim, quando ocupam a coda na nossa língua, tende a ocorrer o processo de inserção vocálica, com vistas à correção dessa estrutura silábica malformada. Mais especificamente, a existência de uma consoante não apta a preencher esse constituinte débil na representação fonológica ocasiona a epêntese ainda durante a silabação, pois essa consoante designada "perdida" não seria ligada a nenhum nó silábico na primeira iteração. Na segunda iteração, porém, uma sílaba estrutural é criada, ainda que desprovida de traços no núcleo vocálico, permitindo que a consoante perdida seja associada à posição de ataque (COLLISCHONN, 2004). Posteriormente, o núcleo dessa sílaba é preenchido com uma vogal por regra de redundância (BISOL, 1999; COLLISCHONN, 2004; SCHNEIDER; SCHWINDT, 2010).

Ao criar uma nova sílaba, a epêntese vocálica promove uma mudança na estrutura silábica da forma subjacente. Dessa forma, as vogais altas /i,u/ (que podem se manifestar como [i] ou [u] em sílabas pretônicas e tônicas, e [I] ou [ひ] em sílabas postônicas), que foram inseridas após [t,d] em 288 das 1.071 ocorrências de $\mathrm{Ct} / \mathrm{d}]_{\circ} \mathrm{C}$, colocam essas consoantes extraviadas no ataque da nova sílaba criada, simplificando, com isso, as codas complexas, travadas por duas obstruintes. Semelhantemente ao processo de epêntese, o apagamento de [t,d] também promove uma alteração na estrutura silábica, já que a coda complexa da entrada também se torna simples na superfície com a eliminação de seu segundo membro, o que ocorreu em $24 \%$ das ocorrências capturadas. De acordo com a análise multivariada realizada pelo Rbrul, o gatilho para aplicação das regras de reparo em codas mediais complexas encerradas em (t) ou (d) envolve a sonoridade das consoantes anteriores a essas oclusivas coronais.

De modo geral, os dados demonstram que a aplicação de estratégias de reparo nas estruturas silábicas de L2 é favorecida quando a oclusiva coronal se encontra 
precedida pelas fricativas desvozeadas /s,f/, com um índice de sonoridade equivalente a 3 - conforme a escala de sonoridade proposta por Parker (2011) -, com peso relativo de 0.81 e $\log$-odds de 1.456. A nasal coronal, que possui uma sonoridade mais elevada, i.e., 7 , também motivou a simplificação das codas complexas, com peso relativo de 0.58 e log-odds de 0.343 , como podemos observar na Tabela 1:

Tabela 1 - Efeitos dos índices de sonoridade das consoantes anteriores a $(\mathrm{t}, \mathrm{d})$ para a aplicação de estratégias de reparo em tais segmentos nas sequências triconsonantais $\mathrm{Ct} / \mathrm{d}] \sigma \mathrm{C}$.

\begin{tabular}{l|c|c|c|c}
\hline \multicolumn{1}{c|}{ Fatores } & $\begin{array}{c}\text { Log- } \\
\text { odds }\end{array}$ & Apl./Total & $\mathbf{\%}$ & Peso Relativo \\
\hline Fricativas desvozeadas /s,f/=3 & 1.456 & $344 / 484$ & 71,1 & .81 \\
\hline Nasal /n/ = 7 & 0.343 & $133 / 306$ & 43,5 & .58 \\
\hline Oclusiva desvozeada /k/ =1 & -0.401 & $43 / 120$ & 35,8 & .40 \\
\hline Aproximante rótica /r/ =11 & -1.398 & $22 / 161$ & 13,7 & .19 \\
\hline \multicolumn{2}{c}{ Gesvio: $1195.852 \quad p<0,001$} & Média: 0.506 \\
\hline
\end{tabular}

Fonte: adaptada de análise no programa Rbrul.

As fricativas desvozeadas /s,f/ apresentam um índice de sonoridade relativamente baixo, com base na hierarquia de sonoridade relativa desenvolvida por Parker (2011), estando acima apenas das oclusivas e das africadas desvozeadas, respectivamente. Assim, as sequências /ft.n/, /ft.f/, /ft.k/, /ft.m/, /st.m/, /st.n/, /st.l/, /st.p/, /st.b/, /st.d/, /st.k/, /st.f/, /st.t/, que apresentam consoantes pós-vocálicas mantendo uma baixa distância de sonoridade (DS) entre si, equivalente a 2 em todos esses casos, foram as mais propensas à aplicação das estratégias de reparo para a simplificação dessas codas complexas.

A Tabela 1 mostra que, das 484 codas mediais encerradas por /t/ precedido por alguma das fricativas desvozeadas /s,f/, 344 ocorrências (71,5\%) sofreram algum tipo de alteração em sua estrutura silábica, seja por meio do apagamento de /t/ ou da inserção vocálica após esse segmento. Mais exatamente, dessas 344 codas em que /t/ se encontrava precedido por /s/ ou por /f/, houve aplicação da regra de inserção vocálica em 164 ocorrências, em comparação com 180 dados contendo apagamento. De fato, a 
palavra "vastness" foi produzida apenas pelos(as) informantes H2, M3 e M8 com epêntese após [t] na coda; em todas as outras 21 saídas desse vocábulo, houve a eliminação de tal som. Com isso, percebemos que diversas palavras, como "swiftness", "liftman", "postman" e "restless", sofreram mais reparos na forma de apagamento ("sof[Ø]ness") ou epêntese ("lift[i]man") que aqueles vocábulos contendo uma aproximante rótica [I] antes de /t,d/, como no caso de "heartbreak", "shortcut" e "hardcover", cujas codas, por sua vez, apresentam uma distância de sonoridade alta (DS $=10$ no caso de [.tt], e DS = 7 em [.rd]).

Assim, o apagamento de /t/ após as fricativas desvozeadas parece atender ao princípio proposto por Clements (1990), designado "Ciclo de Sonoridade", segundo o qual o perfil de sonoridade do tipo silábico preferido nas línguas naturais do mundo apresenta uma diminuição mínima de sonoridade entre os segmentos do núcleo e da coda. Quanto à eliminação de /t,d/ em posição medial de palavras, Raymond, Dautricourt e Hume (2006, p. 55, tradução nossa) esclarecem que, “[e]m codas silábicas, o apagamento resulta da simplificação do encontro consonantal para alcançar a economia gestual e é introduzido durante o planejamento do segmento." Dessa forma, ao invés de cair até o índice mais baixo da hierarquia, essa diminuição quedar-se-ia numa sonoridade um pouco mais elevada, i.e., no terceiro nível da escala, como é possível comparar no Gráfico 2, que traz o movimento de sonoridade na palavra "pos(t)man", com e sem a produção da oclusiva coronal desvozeada, respectivamente: 
Gráfico 2 - Sequência de sonoridade na palavra "pos(t)man".

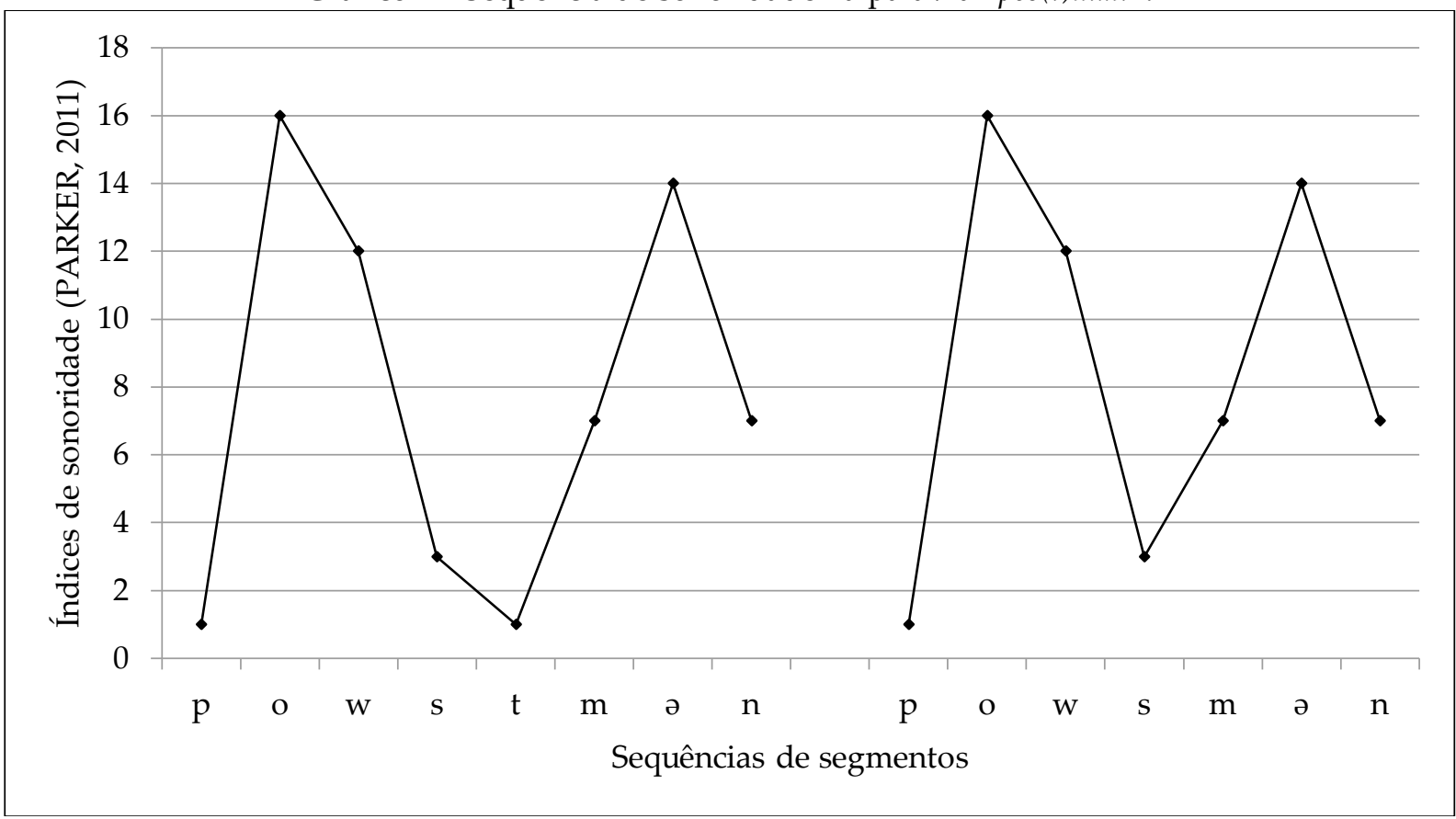

Fonte: elaborado pelos autores.

Observa-se, no Gráfico 2, que a eliminação da oclusiva desvozeada na posição nuclear da sequência consonantal com três membros na palavra "postman" diminui, ainda que sutilmente, o vale que representa a queda de sonoridade da rima na primeira sílaba desse vocábulo. Assim, a sonoridade começa a cair a partir do pico, preenchido pela vogal média [o] no índice 16, e estaciona no índice de valor 3, referente ao da fricativa sibilante [s], não atingindo, com isso, o índice das oclusivas desvozeadas, que corresponde ao nível mais baixo de sonoridade dentre todas classes de sons da fala humana, tais como elencadas na hierarquia de sonoridade relativa proposta por Parker (2011), bem como nas demais escalas desenvolvidas que distinguem as consoantes obstruintes, a propósito.

Os traços fonéticos da consoante anterior exercem influência no apagamento das oclusivas apicais no contexto de encontros consonantais em posição final de palavras no inglês como L1, normalmente obedecendo à seguinte ordem segmental, proposta por Labov (1989, p. 90): /s/ > oclusivas > nasais > outras fricativas > líquidas. Embora a hierarquia alcançada aqui não corresponda fidedignamente à de Labov 
(1989), é possível perceber equivalência ao menos no polo negativo das duas hierarquias, ou seja, no polo que contém sons que desfavorecem o apagamento: fricativas desvozeadas $>$ nasais $>$ oclusivas desvozeadas $>$ líquidas.

Além de uma inversão na prevalência de oclusivas sobre nasais, outra diferença envolve a quarta categoria na ordenação laboviana, i.e., "outras fricativas", que foi alocada junto com /s/ na primeira posição do nosso modelo, o que nos leva a inferir que a sonoridade, de fato, desempenha um papel fundamental na aplicação da regra variável na interlíngua de aprendizes campinenses de inglês como L2, ao invés do modo de articulação por si só, haja vista a falta de distinção entre consoantes vozeadas e desvozeadas na hierarquia segmental de Labov (1989). Na verdade, parece não existir acordo no que se refere às distinções necessárias às classes naturais em termos de sonoridade: há escalas que não distinguem as obstruintes ou as líquidas, como a de Clements (1990, p. 292): $\mathrm{O}<\mathrm{N}<\mathrm{L}<\mathrm{G}<\mathrm{V}$. Outras, mais detalhadas, distinguem as obstruintes e as vogais, como a de Jespersen (1904 apud CLEMENTS, 1990, p. 285): (a) oclusivas desvozeadas; (b) fricativas desvozeadas $>$ oclusivas vozeadas $>$ fricativas vozeadas > (a) nasais vozeadas; (b) laterais vozeadas > sons de [r] vozeados > vogais altas > vogais médias > vogais baixas. Ainda assim, essa escala não especifica a posição dos glides e das africadas, por exemplo.

Ainda em relação à questão da sonoridade, sugerimos que as sequências contendo consoantes com uma distância maior de sonoridade entre os membros das codas, por serem menos marcadas, tenderiam a apresentar menos dificuldades de pronúncia para aprendizes de L2, de modo geral, na medida em que as sequências consonantais não são adquiridas todas do mesmo modo: a marcação baseada na sonoridade parece desempenhar um papel decisivo na interlíngua de aprendizes de L2, como defendem Sperbeck e Strange (2010) em sua discussão acerca de pesquisas com foco na produção de ataques complexos em L2. Já os encontros consonantais em codas com distâncias menores e platôs, por serem respectivamente mais marcados, 
seriam mais suscetíveis a reparos na interlíngua de aprendizes campinenses de inglês como L2, seguindo a tendência observada tanto nas variedades do círculo interno quanto no contexto das novas variedades do inglês (WILTSHIRE, 2014). Os resultados obtidos aqui corroboram essa hipótese apenas parcialmente.

Primeiramente, as codas com uma distância de sonoridade alta entre seus membros, quais sejam, /rt/ e /rd/, não favoreceram, de fato, a aplicação de estratégias de reparo, tendo ocorrido em apenas 22 das 161 ocorrências, o que corresponde a 13,7 \%, com peso relativo de 0.19 e $\log$-odds ${ }^{9} \mathrm{de}-1.398$. Essa taxa dialoga com as observações amplamente disseminadas na literatura de que a líquida /r/ não promove o apagamento das oclusivas coronais (GUY; BOBERG, 1997). Segundamente, os encontros consonantais com uma distância de sonoridade baixa, como é o caso daqueles formados por /s,f/ antes de /t/ $(\mathrm{DS}=2)$, engatilharam a aplicação de regras com vistas à simplificação da coda, como revelam 344 das 484 ocorrências, o que representa 71,1 \% desse total, apresentando peso relativo de 0.81 e log-odds de 1.456 . Contudo, os encontros consonantais contendo platôs nas codas, a exemplo de $/ \mathrm{kt} /$, não foram os que mais promoveram reparos, como esperado. $\mathrm{O}$ fato de que $/ \mathrm{kt} / \mathrm{se}$ manteve inalterado em 77 das 120 ocorrências (64,2 \%), em comparação com 30 casos de epêntese e 13, de apagamento, mesmo correspondendo a uma estrutura mais marcada, pode ser interpretado, a nosso ver, pelo fenômeno de Afrouxamento da Condição de Coda (ACC).

Embora nunca cheguem a fazer parte do mesmo constituinte silábico no PB, as consoantes /k/ e /t/ podem ocorrer juntas sem acrescentamento de substância fonética, sobretudo em posição medial de palavras, como em "fac.ção", "pac.to", "op.ção" e "rép.til", por exemplo. Apesar da possibilidade (ou mesmo da tendência!) de se ouvir

\footnotetext{
9 Os coeficientes do modelo de regressão designados "log-odds" medem a magnitude do efeito e fornecem a mesma informação que os pesos relativos, embora numa escala infinita de números negativos (que indicam desfavorecimento do fator para o condicionamento da variação) e positivos (que revelam favorecimento). Já um valor equivalente a zero sugere neutralidade (JOHNSON, 2015).
} 
uma vogal após $/ \mathrm{k} /$, existe também um movimento, sobretudo em contextos mais formais de comunicação, de buscar silenciar a manifestação de tal vogal, afrouxando a condição de coda, que não licencia obstruintes no PB (com exceção de /S/). De fato, esse fenômeno variável foi investigado por Lucena e Alves (2010), que realizaram uma pesquisa sociolinguística buscando verificar, dentre outros objetivos, a ocorrência do ACC nos dialetos gaúcho e paraibano, tais como falados por 22 estudantes de cursos de graduação em Letras naturais das regiões de Pelotas (RS) e de Guarabira (PB). Os pesquisadores observam que "[...] o dialeto paraibano apresenta peso relativo de 0,55 para aplicação da regra de epêntese, enquanto que o dialeto gaúcho apresenta 0,44" (LUCENA; ALVES, 2010, p. 38). Assim, houve o acréscimo de elemento epentético em 141 das 253 ocorrências analisadas do falar gaúcho (55,7 \%), em comparação com 178 dados de inserção vocálica do total de 271 no falar paraibano $(65,7$ \%), o que revela a ocorrência de sílabas fechadas em 34,3 \% das saídas em L1 produzidas por falantes paraibanos(as), mesmo considerando que “[...] a variante gaúcha fica mais à vontade com sílabas travadas com coda" (LUCENA; ALVES, 2010, p. 38).

Diante de tal evidência e dos resultados obtidos em nosso estudo, julgamos ser esse processo variável possivelmente atuante no dialeto do grupo de informantes investigado aqui, sobretudo no contexto de obstruintes encerrando codas mediais, como no caso dos vocábulos supramencionados, que podem ser ouvidos como

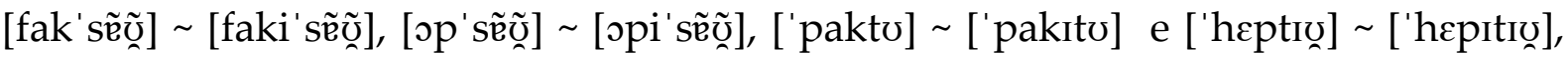
respectivamente, em detrimento das obstruintes em codas finais, que tendem a ser ouvidas com inserção vocálica, como ocorreu nos vocábulos "Unimed[I]”, "Varig[I]” e "sob[I]" (cf. REIS, 2019). No que concerne aos dados em português, 34,2 \% das 960 ocorrências coletadas com metade dos(as) participantes apresentam acrescentamento de substância fonética, enquanto 65,8 \% evidenciam enfraquecimento da coda, ou seja, apenas 328 demonstram a ocorrência de uma vogal anterior (sobretudo, [i] e [I], mas também [e] em alguns casos). Conjecturamos, portanto, que esse afrouxamento 
percebido tanto em anglicismos quanto em palavras dicionarizadas do português se manifeste também na interfonologia dos(as) falantes campinenses de L2, revelando, com isso, uma transferência da L1, sobretudo no caso de aprendizes em estágios iniciais de proficiência que ainda não tenham adquirido conhecimentos relativos às diferentes estruturas presentes no sistema fonológico da língua-alvo, cujos efeitos são discutidos em seguida.

\subsection{Nível de proficiência em L2}

As pesquisas em aquisição de L2 tendem a demonstrar comportamentos variáveis distintos, dependendo do nível de proficiência em que se encontram aprendizes brasileiros(as) de inglês. Assim, a proficiência dos(as) aprendizes campinenses de inglês como L2 foi classificada neste estudo em três níveis, quais sejam: básico, intermediário e avançado. Essa divisão é bastante disseminada nos estudos sociolinguísticos (LIMA, 2012; ALVES; LUCENA, 2014; GOMES, 2014; NASCIMENTO, 2015), de modo geral, e foi determinada aqui com base na pontuação em teste de proficiência: todos(as) os(as) 24 participantes se submeteram ao Oxford Placement Test (ALLAN, 2004), que diz respeito a um teste de proficiência em inglês validado em mais de 30 países, contendo um total de 200 questões de múltipla escolha, sendo 100 delas na seção de gramática e as outras 100, na de compreensão oral.

A Tabela 1 mostra precisamente a forma como se deu a estratificação dos 24 indivíduos nos três níveis supramencionados ${ }^{10}$, de acordo com a pontuação obtida no teste:

\footnotetext{
10 Convém ressaltar que os níveis estabelecidos nas orientações fornecidas por Allan (2004) compreendem dez classificações para os(as) usuários(as) de inglês, desde "iniciante" até "funcionalmente bilíngue".
} 
Tabela 4 - Níveis de proficiência de acordo com pontuação obtida em teste.

\begin{tabular}{c|c}
\hline Pontuação & Nível de proficiência \\
\hline $0-119$ & Básico \\
\hline $120-149$ & Intermediário \\
\hline $150-200$ & Avançado \\
\hline
\end{tabular}

Fonte: Adaptada de Dabbagh e Noshadi (2014).

Como visto no Quadro 2, a única variável externa de efeito fixo selecionada como tendo efeito significativo no uso de estratégias de reparo em sequências triconsonantais $\mathrm{Ct} / \mathrm{d}]_{\sigma} \mathrm{C}$ compreende os níveis de proficiência em L2, ficando atrás da sonoridade de consoantes anteriores e posteriores, respectivamente. Vejamos os dados na Tabela 5:

Tabela 5 - Efeito dos níveis de proficiência na simplificação da coda medial complexa $\mathrm{Ct} / \mathrm{d}]_{\sigma}$.

\begin{tabular}{l|c|c|c|c}
\hline \multicolumn{1}{c|}{ Fatores } & Log-odds & Apl./Total & $\%$ & Peso Relativo \\
\hline Básico & 0.679 & $227 / 356$ & 63,8 & .66 \\
\hline Intermediário & -0.246 & $165 / 359$ & 46 & .44 \\
\hline Avançado & -0.433 & $150 / 356$ & 42,1 & .39 \\
\hline \multicolumn{2}{r|}{ Desvio: 1195.852} & Graus de liberdade: 2 & $p<0,001$ & Média: 0.506 \\
\hline
\end{tabular}

Fonte: adaptada de análise no programa Rbrul.

Como podemos perceber, das 356 ocorrências do fenômeno produzidas por informantes que obtiveram uma pontuação entre 0 e 119 no Oxford Placement Test (ALLAN, 2004), houve aplicação de epêntese vocálica e apagamento em 227 sequências $\mathrm{Ct} / \mathrm{d}]_{\circ} \mathrm{C}$, o que representa 63,8 \% desses dados, com peso relativo de $0.66^{11}$ e log-odds de 0.679 , demonstrando, portanto, uma propensão por parte de aprendizes

\footnotetext{
${ }^{11}$ Peso relativo (PR) corresponde a uma medida probabilística cujo valor está sempre compreendido no intervalo entre zero e um (GUY; ZILLES, 2007). No caso de uma análise binária, o ponto neutro equivale a 0,50, o que significa que um fator com tal valor matemático não tem efeito sobre o uso da variante investigada, ou seja, nem favorece nem desfavorece sua aplicação. Fatores que apresentam valores superiores a 0,50 são interpretados como sendo favoráveis ao uso de uma dada variante - como é o caso do nível básico em relação à aplicação de estratégias de reparo nas sequências triconsonantais $\mathrm{Ct} / \mathrm{d}]_{\circ} \mathrm{C}$ -, ao passo que fatores com um valor de PR menor que o do ponto neutro - como ocorre com os níveis intermediário e avançado, por exemplo - desfavorecem o uso de tais regras, por exercer pouco efeito sobre a variante observada.
} 
de nível básico ao uso de regras com vistas ao ajuste dessas estruturas silábicas marcadas e inexistentes no PB. Mais especificamente, aprendizes de nível básico lançaram mão da estratégia de epêntese mais fortemente, ao passo que os(as) de níveis intermediário e avançado, por sua vez, recorreram de modo relativamente mais acentuado à regra de apagamento, como é possível comparar no Gráfico 3:

Gráfico 3 - Uso das variantes segundo os níveis de proficiência em L2.

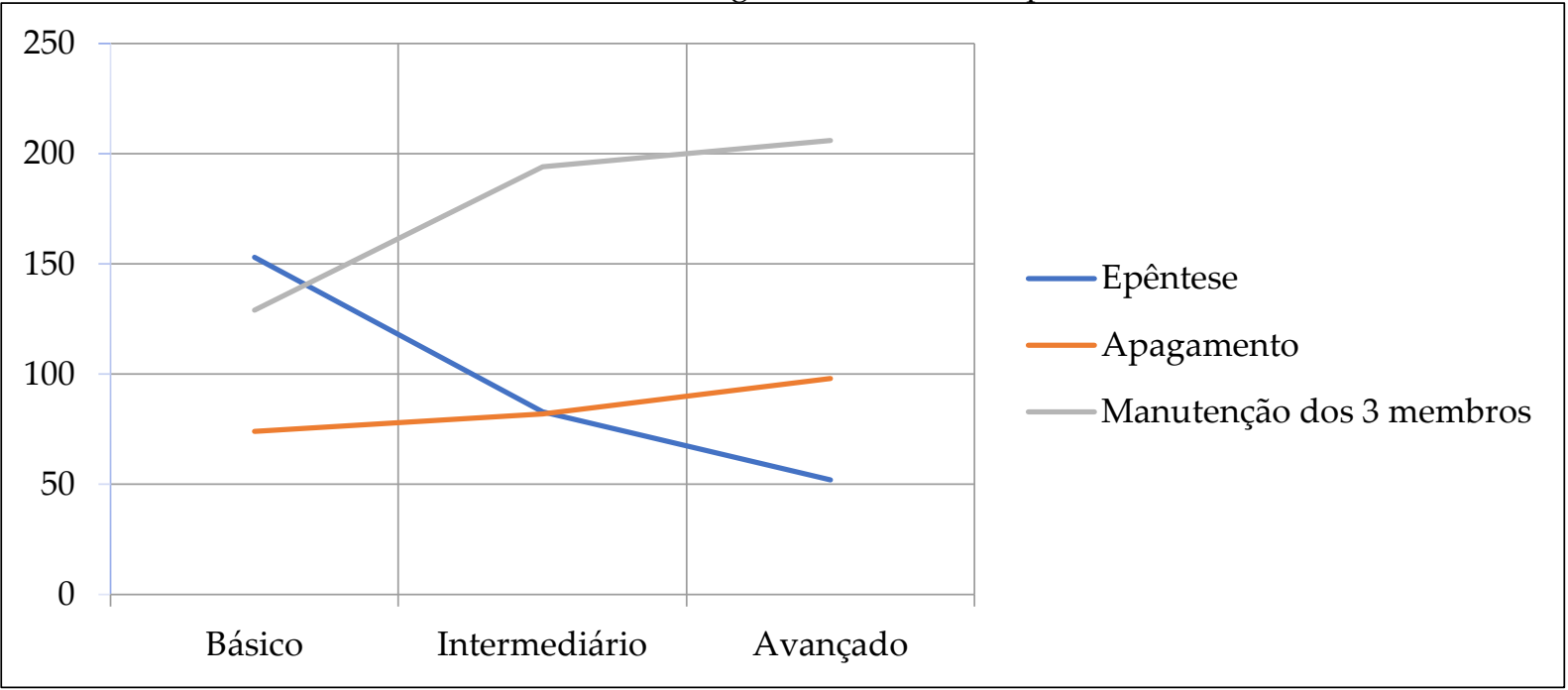

Fonte: elaborado pelos autores.

O Gráfico 3 mostra que a aplicação da regra de epêntese está em uma relação inversamente proporcional ao nível de proficiência em L2: há um declínio acentuado na criação de uma estrutura silábica adicional nas saídas em L2 conforme aumenta o nível de proficiência do grupo de informantes. Em termos numéricos, isso significa que aprendizes com desempenho classificado como básico inseriram vogais epentéticas em 153 dos 227 dados produzidos pelo grupo com aplicação de estratégias, enquanto informantes com habilidades linguísticas intermediárias aplicaram epêntese em 83 das 165 ocorrências com estruturas silábicas alteradas e, por fim, participantes de nível avançado produziram apenas 52 sequências $\mathrm{Ct} / \mathrm{d}]_{\odot} \mathrm{C}$ com inserção silábica, tendo havido aplicação da regra de apagamento nas outras 98 saídas com reajustes na coda medial complexa encerrada em $(-t, d)$. 
No que se refere à regra de apagamento, há, portanto, uma tendência contrária àquela observada nos dados de epêntese: à medida que o nível de proficiência aumenta, há um leve aumento no emprego da regra de apagamento de (-t,d) na coda medial complexa $\mathrm{Ct} / \mathrm{d}]_{\sigma}$, tendo a elisão sido progressivamente aplicada pelos indivíduos dos níveis básico, intermediário e avançado em 74, 82 e 98 dados dos totais de 227, 165 e 150 ocorrências com aplicação da variante delimitada em cada grupo, respectivamente.

Também chama a atenção o fato de que há um crescimento na manutenção das saídas em L2 com os três membros presentes na entrada, à medida que aumenta o nível de proficiência do grupo de informantes. Assim, dos 356 dados produzidos por oito informantes de nível avançado, 206 são fiéis às entradas. No que concerne às produções no fator intermediário, 194 contêm os três membros das sequências triconsonantais, uma quantidade levemente menor. Contudo, já se percebe uma diminuição na quantidade de saídas fiéis dentre aprendizes com desempenho mais elementar: das 356 saídas, 129 não sofreram alterações.

Esses resultados indicam, portanto, que há uma inter-relação entre as habilidades linguísticas da população de informantes e a aplicação de estratégias de reparo. Levando-se em conta a amalgamação das regras de epêntese e de apagamento na variável dependente "aplicação de estratégias de reparo em $\mathrm{Ct} / \mathrm{d}]_{\circ} \mathrm{C}$ vs. não aplicação de ajustes", para a rodada binária, podemos constatar que há uma relação inversamente proporcional entre o emprego de tais estratégias e o nível de proficiência em L2, já que os índices são relativamente menores para o grupo avançado: 42,1\% dos 356 dados apresentam reajustes na coda medial complexa, com peso relativo de 0.39 e $\log$-odds de -0.433 , o que demonstra desfavorecimento no contexto de tais falantes. As taxas referentes ao grupo de intermediário, por sua vez, são levemente maiores, tendo havido 165 dados com aplicação de regras, o que representa 46\% de um total de 359, com peso relativo de 0.44 e log-odds de -0.246 , que também caracteriza tal grupo como 
inibidor. Por fim, o grupo de aprendizes de nível básico usou a variante "aplicação de estratégias de reparo em $\mathrm{Ct} / \mathrm{d}]_{\odot} \mathrm{C}^{\prime \prime}$ em $63,8 \%$ de todas as 356 ocorrências produzidas, com peso relativo de 0.66 e log-odds de 0.679 , o que revela um favorecimento à aplicação de reparos por parte de falantes com tal desempenho em L2.

\section{Considerações finais}

Por se tratar de um sistema linguístico evolutivo inerente a aprendizes de L2, o qual está associado tanto à L1 desses indivíduos quanto à L2 que está sendo aprendida, mas que, no entanto, se distingue dessas línguas, a interlíngua se configura como uma língua única e individual (NOYAU, 1990 apud BAYLEY, 2007) que também apresenta padrões variáveis - assim como ocorre com as demais línguas naturais -, os quais são condicionados tanto por fatores linguísticos relativos a ambas as línguas como, também, por fatores externos ao sistema, incluindo aqueles de natureza situacional, contextual, social e cognitiva. Assim, constatamos o emprego de três variantes, as quais são caracterizadas pela: (1) manutenção das três consoantes nas sequência, sem aplicação de qualquer regra, i.e., $\mathrm{Ct} / \mathrm{d}]_{\sigma} \mathrm{C}$; (2) inserção vocálica após [-t,d], com aplicação da regra de epêntese vocálica, ou seja, $\varnothing \rightarrow \mathrm{i} /[-$ soan, - cont, +cor $\left.] \_\right] \sigma$; e, por fim, (3) simplificação da coda medial complexa através do apagamento das oclusivas coronais, isto é, [-soan, - cont, + cor $] \rightarrow \varnothing /[+$ cons $\left.] \_\right] \sigma$.

Julgamos que a seleção da sonoridade das consoantes anteriores como sendo uma variável estatisticamente significativa pelo programa reforça o status da coda na condição de subconstituinte silábico, tendo em vista que as consoantes que entram em contato em tal posição obedecem a fortes restrições fonotáticas, ao contrário da maior liberdade observada no que concerne às consoantes posteriores a $(t, d)$, as quais, por sua vez, fazem parte do ataque de outra sílaba, que geralmente corresponde a um segundo morfema nas palavras, podendo este elemento fazer parte de sufixos 
inflexionais, no caso de vocábulos derivados (-ful, -less, -ly, -ness, etc.), ou de cabeças, em se tratando de substantivos compostos (-bag, -coat, etc.).

As codas com uma distância de sonoridade alta entre seus membros, como /rt/ e /rd/, não favoreceram a aplicação de estratégias de reparo, tendo ocorrido em apenas 22 das 161 ocorrências, o que corresponde a 13,7\%, com peso relativo de 0.19 e log-odds de -1.398. Já os encontros consonantais com uma distância de sonoridade baixa, como é o caso daqueles formados por /s,f/ antes de /t/ $(D S=2)$, engatilharam a aplicação de regras com vistas à simplificação da coda, como revelam 344 das 484 ocorrências. Porém, os encontros com platôs nas codas, como / kt/, não foram os que mais promoveram reparos, como esperado. $\mathrm{O}$ fato de que $/ \mathrm{kt} /$ manteve-se inalterado em 77 das 120 ocorrências, em comparação com 30 casos de epêntese e 13, de apagamento, pode ser justificado, a nosso ver, pelo fenômeno de ACC.

Observamos também que os princípios universais para a boa formação da sílaba parecem ter se sobreposto aos filtros específicos de língua particular. Portanto, a aplicação da regra de apagamento por parte do grupo de 24 informantes pode nos levar a supor que as saídas produzidas por tais aprendizes revelam que o reparo nas produções das sequências $\mathrm{Ct} / \mathrm{d}]_{\odot} \mathrm{C}$ está condicionado, sobretudo, pela sonoridade, seguindo princípios universais de boa formação da sílaba, a exemplo do PSS, além dos outros fatores, como a falta de familiaridade com a estrutura da L2 no nível básico, já que 63,8 \% das 356 produções dessas sequências triconsonantais apresentaram reparos na coda medial complexa, com peso relativo de 0.66 .

Diferentemente do esperado, o percurso de aquisição de tal estrutura não envolve um movimento progressivo em direção à redução de uma sequência marcada com três membros para um contato silábico entre duas consoantes, como se poderia conjecturar fundamentado no fato de que aprendizes de nível básico usaram mais a estratégia de epêntese, ao passo que falantes de níveis intermediário e avançado empregaram mais a regra de apagamento, respectivamente. Contudo, embora os 
dados de sequências inalteradas referentes aos níveis intermediário e avançado sejam levemente maiores que os do básico, em todos esses três casos, a não aplicação de estratégias de reparo foi superior ao número de aplicação de apagamento e epêntese, de modo que nossos dados nos permitem supor o seguinte percurso de aquisição das sequências $\mathrm{Ct} / \mathrm{d}]_{\odot} \mathrm{C}$ em palavras como "postman": post[I]man $\rightarrow$ pos[ø]man $\rightarrow$ postman.

Portanto, as saídas produzidas por 24 aprendizes campinenses de inglês como L2 revelam que os ajustes nas produções das sequências $\mathrm{Ct} / \mathrm{d}]_{{ }_{\odot} \mathrm{C}}$ estão condicionados pela sonoridade, seguindo princípios universais de boa formação da sílaba, a exemplo do PSS, e também pela aparente falta de familiaridade com o sistema fonológico da L2, como no caso de aprendizes de desempenho mais elementar. Esses fatores agem em conjunto em estágios iniciais da aquisição de tais sequências, chegando a estágios mais avançados com menos força, o que possibilita a retenção de três consoantes numa estrutura mais marcada, talvez num movimento em direção a uma dicção mais aperfeiçoada em L2.

\section{Referências Bibliográficas}

ALLAN, D. Oxford Placement Test 1. Oxford: Oxford University Press, 2004.

ALVES, F. C.; LUCENA, R. M. Aquisição da lateral silábica do inglês: uma análise via Teoria da Otimalidade Estocástica. Letrônica (PUC-RS), Porto Alegre (RS), v. 7, n. 2, jul./dez., p. 795-820, 2014. DOI https://doi.org/10.15448/1984-4301.2014.2.17920

BAYLEY, R. Second language acquisition: a variationist perspective. In: BAYLEY, R.; LUCAS, C. (ed.). Sociolinguistic Variation: Theories, methods and applications. Cambridge: Cambridge University Press, 2007. p. 133-144. DOI https://doi.org/10.1017/CBO9780511619496

BERG, T. Linguistic Structure and Change: An Explanation from Language Processing. Oxford: Oxford University Press, 1998.

BISOL, L. Introdução a estudos de fonologia do português brasileiro. Porto Alegre: EDIPUC - RS, 1996. 
BISOL, L. A sílaba e seus constituintes. In: NEVES, M. H. M. (org.). Gramática do português falado. v. 7: Novos Estudos. Campinas: Ed. da Unicamp, 1999. p. 701-742.

BLEVINS, J. The independent nature of phonotactic constraints: an alternative to syllable-based approaches. In: FÉRY, C.; van de VIJVER, R. (ed.). The Syllable in Optimality Theory. Cambridge: Cambridge University Press, 2003. p. 375-403. DOI https://doi.org/10.1017/CBO9780511497926.016

BOERSMA, P.; WEENINK, D. Praat: Doing phonetics by computer [Computer program]. Version 5.3.56. 2013. Disponível em: http://www.fon.hum.uva.nl/praat/.

CEDERGREN, H. J.; SANKOFF, D. Variable rules: performance as a statistical reflection of competence. Language, v. 50, n. 2., p.333-355, 1974. DOI https://doi.org/10.2307/412441

CLEMENTS, G. N. The role of the sonority cycle in core syllabification. In: KINGSTON, J.; BECKMAN, M. E. (ed.) Papers in Laboratory Phonology I: Between the grammar and physics of speech. Cambridge, CUP, 1990. p. 283-333. DOI https://doi.org/10.1017/CBO9780511627736.017

COLLINS, B.; MEES, I. The Sounds of English and Dutch. The Hague: Leiden University Press, 1981.

COLLISCHONN, G. Epêntese Vocálica e Restrições de Acento no Português do Sul do Brasil. Signum: Estudos da Linguagem, Londrina, n. 7, pt. 1, p. 61-78, jun. 2004. DOI https://doi.org/10.5433/2237-4876.2004v7n1p61

CRUTTENDEN, A. Gimson's Pronunciation of English. $8^{\text {th }}$ edition. London: Arnold, 2014. DOI https://doi.org/10.4324/9780203784969

CSIDES, C. A Typology of English Consonant Clusters. Proceedings of the International Conference on English Language and Literatures in English 3 (ELLE 3). Kolozsvár (Cluj-Napoca): Casa Cartii Stiinja, 2013. p. 49-56.

DABBAGH, A.; NOSHADI, M. Crossing metacognitive strategy awareness in listening performance: An emphasis on language proficiency. International Journal of Applied Linguistics and English Literature, v. 3, n. 6, p. 234-242, 2014. DOI https://doi.org/10.7575/aiac.ijalel.v.3n.6p.234

GOLDSMITH, J. A. Phonological theory. In: GOLDSMITH, J. A. (ed.) The handbook of phonological theory. Oxford, Blackwell, 1995. p. 1-23. 
GOMES, A. A. A. A epêntese vocálica inicial em clusters sC por aprendentes brasileiros de inglês como LDE. Dissertação (Mestrado em Linguística). João Pessoa: UFPB, 2014.

GUY, G.; ZILLES, A. Sociolinguística quantitativa: instrumental de análise. São Paulo: Parábola Editorial, 2007.

GUY, G.; BOBERG, C. Inherent variability and the Obligatory Contour Principle. Language Variation and Change, v. 9, n. 2, 1997. p. 149-164. DOI https://doi.org/10.1017/S095439450000185X

HAMMOND, M. The phonology of English: a prosodic optimality-theoretic approach (The Phonology of the World's Languages). Oxford: Oxford University Press, 1999.

HORA, D. da. Fricativas coronais: análise variacionista. In: RONCARATI, C.; ABRAÇADO, J. (org.). Português brasileiro: contato linguístico, heterogeneidade e história. Rio de Janeiro: Letras, 2003.

HOSMER, D. W.; LEMESHOW, S. Applied logistic regression. $2^{\text {nd }}$ ed. New York: Wiley, 2000. DOI https://doi.org/10.1002/0471722146

JOHNSON, D. E. Rbrul version 2.29: A variable rule application in R. 2015.

KENT, R. D.; READ, C. Análise Acústica da Fala. Tradução de Alexsandro Meireles. São Paulo: Cortez, 2015.

LABOV, W. The child as linguistic historian. Language Variation and Change, n. 1, 1989. p. 85-97. DOI https://doi.org/10.1017/S0954394500000120

LIMA, L. A. S.; LUCENA, R. M. Processo de monotongação no brejo paraibano: uma análise variacionista. In: 60 Reunião Anual da SBPC - Sociedade Brasileira para o Progresso da Ciência, 2008, Campinas, SP. Anais/Resumos da 60. Reunião Anual da SBPC: Publicação eletrônica, 2008.

LIMA, L. A. S. Epêntese vocálica medial: uma análise variacionista da influência da língua materna (L1) na aquisição de inglês (L2). Dissertação (Mestrado em Linguística). João Pessoa: UFPB, 2012. 
LUCENA, R. M.; ALVES, U. K. Implicações dialetais (dialeto gaúcho vs. paraibano) na aquisição de obstruintes em coda por aprendizes de inglês (L2): uma análise variacionista. Revista Letras de Hoje, Porto Alegre (RS), v. 45, n. 1, p. 35-42, 2010.

MASSINI-CAGLIARI, G. A música da fala dos trovadores: desvendando a prosódia medieval. São Paulo: Editora Unesp, 2015. DOI https://doi.org/10.7476/9788568334584

MAZZONI, D.; DANNENBERG, R. et al. Audacity [Computer program]. Version 2 (2.0.6). 2014. Disponível em: http://www.audacityteam.org/.

NASCIMENTO, G. C. A. Epêntese vocálica em encontros consonantais por falantes brasileiros de inglês como língua estrangeira. 152 f. Dissertação (Mestrado em Linguística e Língua Portuguesa) - Faculdade de Ciências e Letras, Universidade Estadual Paulista "Júlio de Mesquita Filho", Araraquara, 2015.

PARKER, S. Sonority. In: van OOSTENDORP, M. et al. (ed.). The Blackwell Companion to Phonology, Volume II. 2011. p. 1.160-1.184. DOI https://doi.org/10.1002/9781444335262.wbctp0049

PIERREHUMBERT, J. B. Syllable Structure and Word Structure: a Study of Triconsonantal clusters in English. In: KEATING, P. (ed.). Phonological Structure and Phonetic Form: Papers in Laboratory Phonology III. Cambridge, UK: Cambridge University Press, 1994. p. 168-188. DOI https://doi.org/10.1017/CBO9780511659461.011

PULGRAM, E. Consonant cluster, consonant sequence and the syllable. Phonetica, v. 13, n. 1-2, p. 76-81, 1965. DOI https://doi.org/10.1159/000258473

RAYMOND, W. D.; DAUTRICOURT, R.; HUME, E. Word-internal /t,d/ deletion in spontaneous speech: Modeling the effects of extra-linguistic, lexical, and phonological factors. Language Variation and Change, v. 18, n. 1., p. 55-97, 2006. DOI https://doi.org/10.1017/S0954394506060042

R CORE TEAM. R: A language and environment for statistical computing. $R$ Foundation for Statistical Computing. Viena, Áustria. 2018. Disponível em: https://www.R-project.org.

REIS, F. S. dos. Aquisição variável de sequências triconsonantais $\mathrm{Ct} / \mathrm{d}]_{\sigma} \mathrm{C}$ por falantes campinenses de inglês como L2. Tese (Doutorado em Linguística). João Pessoa: UFPB, 2019. 
ROBERTS, J. Acquisition of Variable Rules: (-t,d) deletion and (ing) production in preschool children. Doctoral dissertation, University of Pennsylvania, 1994.

SANKOFF, D.; TAGLIAMONTE, S. A.; SMITH, E. GoldVarb X: a variable rule application for Macintosh and Windows. Department of Linguistics, University of Toronto, 2005.

SELKIRK, E. The syllable. In: HULST van der, H.; SMITH, N. (ed.) The structure of phonological representations II. Dordrecht: Foris, 1982. p. 337-383.

SELKIRK, E. The Prosodic Structure of Function Words. In: McCARTHY, J. (ed.). Optimality Theory in Phonology: A Reader, Blackwell Publishing, 2003. p. 464-482. DOI https://doi.org/10.1002/9780470756171.ch25

SCHNEIDER, A.; SCHWINDT, L. C. S. A epêntese vocálica medial em PB e na aquisição de inglês como LE: uma análise morfofonológica. Letras de Hoje, Porto Alegre, v. 45, n. 1, p. 16-26, jan./mar. 2010.

SPERBECK, M.; STRANGE, W. The perception of complex onsets in English: universal markedness? Proceedings of the 33rd Annual Penn Linguistics Colloquium, 16.1. 2010. p. 194-204.

SZIGETVÁRI, P. Branching onsets and syncope in English. Language sciences, v. 29. Elsevier. p. 408-425, 2007. DOI https://doi.org/10.1016/j.langsci.2006.12.015

TEMPLE, R. A. M. ( $t, d)$ : The Variable Status of a Variable Rule. Oxford University Working Papers in Linguistics, Philology and Phonetics. 2009. p. 145-170.

WILTSHIRE, C. New Englishes and the emergence of the unmarked. In: GREEN, E.; MEYER, C. F. (ed.). The variability of current World Englishes. Berlin: De Gruyter, 2014. p. 13-38.

XAVIER, M. F.; MATEUS, M. H. (org.). Dicionário de termos linguísticos, volume I. Lisboa: Edições Cosmos, 1990. 


\section{ANEXOS}

Anexo A - Palavras do corpus de língua inglesa.

\begin{tabular}{|c|c|c|c|c|}
\hline \multicolumn{2}{|c|}{$\begin{array}{l}\text { Contexto fonológico } \\
\text { precedente }\end{array}$} & Consoante perdida & \multicolumn{2}{|c|}{$\begin{array}{c}\text { Contexto fonológico } \\
\text { seguinte }\end{array}$} \\
\hline \multicolumn{2}{|c|}{ Obstruintes } & $(t)$ & & Obstruintes \\
\hline Coronal & /s/ & Postpone; Trustful; Textbook & $/ p, f, b /$ & Labial \\
\hline Coronal & /s/ & Christchurch; Nextdoor & $/ \mathrm{d}, \mathrm{g} /$ & Coronal \\
\hline Coronal & /s/ & Postcard; Waistcoat & $/ \mathrm{k} /$ & Dorsal \\
\hline Dorsal & $/ \mathrm{k} /$ & Respectful; Neglectful & $/ \mathrm{f} /$ & Labial \\
\hline Labial & /f/ & Softshell; Giftshop & $\mid \mathrm{s} /$ & Coronal \\
\hline Labial & $/ \mathrm{f} /$ & Softcover; Softcore & $/ \mathrm{k} /$ & Dorsal \\
\hline \multicolumn{2}{|c|}{ Obstruintes } & (t) & \multicolumn{2}{|r|}{ Soantes } \\
\hline Coronal & $/ \mathrm{s} /$ & Christmas; Postman & $/ \mathrm{m} /$ & Labial \\
\hline Coronal & $/ \mathrm{s} /$ & Vastness; Restless & $/ \mathrm{n}, \mathrm{l} /$ & Coronal \\
\hline Dorsal & $/ \mathrm{k} /$ & Exactly; Correctly; Perfectly & $/ 1 /$ & Coronal \\
\hline Labial & $/ \mathrm{f} /$ & Swiftness; Softness & $/ \mathrm{n} /$ & Coronal \\
\hline Labial & $/ \mathrm{f} /$ & Liftman; Leftmost & $/ \mathrm{m} /$ & Labial \\
\hline \multicolumn{2}{|c|}{ Soantes } & (t) & \multicolumn{2}{|r|}{ Obstruintes } \\
\hline Coronal & $/ \mathrm{n} /$ & Countdown; Saintdom & $/ d /$ & Coronal \\
\hline Coronal & $/ \mathrm{r} /$ & Shortcut; Shortcake & $/ \mathrm{k} /$ & Dorsal \\
\hline Coronal & $/ \mathrm{r} /$ & Heartbreak; Dirtbag & $/ \mathrm{b} /$ & Labial \\
\hline \multicolumn{2}{|c|}{ Soante } & $(t)$ & \multicolumn{2}{|r|}{ Soante } \\
\hline Coronal & $/ \mathrm{r} /$ & Partly; Courtroom & $/ 1, \mathrm{r} /$ & Coronal \\
\hline \multicolumn{2}{|c|}{$\begin{array}{c}\text { Contexto fonológico } \\
\text { precedente }\end{array}$} & Consoante perdida & \multicolumn{2}{|c|}{$\begin{array}{c}\text { Contexto fonológico } \\
\text { seguinte }\end{array}$} \\
\hline \multicolumn{2}{|c|}{ Soantes } & (d) & \multicolumn{2}{|c|}{ Obstruintes } \\
\hline Coronal & $/ \mathrm{n}, \mathrm{r} /$ & $\begin{array}{l}\text { Grandkid; Hardcover; } \\
\text { Handkerchief; Handcuff }\end{array}$ & $/ \mathrm{k} /$ & Dorsal \\
\hline Coronal & $/ \mathrm{n} /$ & Handbag; Sandpiper & $/ \mathrm{b}, \mathrm{p} /$ & Labial \\
\hline \multicolumn{2}{|c|}{ Soantes } & (d) & \multicolumn{2}{|r|}{ Soantes } \\
\hline Coronal & $/ \mathrm{n} /$ & Kindness; Blindness & $/ \mathrm{n} /$ & Coronal \\
\hline Coronal & $/ \mathrm{n} /$ & Bandwidth & $/ \mathrm{w} /$ & Dorsal \\
\hline Coronal & $/ \mathrm{n} /$ & Grandmother; Amendment & $/ \mathrm{m} /$ & Labial \\
\hline
\end{tabular}

